\title{
EL PUBLIC SECTOR PURCHASE PROGRAMME (PSPP) A LA LUZ DE LAS JURISPRUDENCIAS DEL TJUE Y DEL TRIBUNAL CONSTITUCIONAL FEDERAL ALEMÁN: ANTECEDENTES Y CONSECUENCIAS DE LA SENTENCIA DEL BVERFG DE 5 DE MAYO DE 2020 (2 BVR 859/15) JUSTO CORTI VARELA ${ }^{1}$ jcorti@der.uned.es
}

\section{Resumen}

La sentencia del 5 de mayo de 2020 del Tribunal Constitucional Federal Alemán (BVerfG) que declara ultra vires al Public Sector Purchase Programme (PSPP) del BCE, y a la sentencia Weiss del TJUE que lo había validado, constituye un punto de inflexión en el llamado "diálogo" entre ambos tribunales. Las discrepancias en torno al alcance del mandato del BCE (art. 127 TFUE), y en particular a cómo aplicarle el principio de proporcionalidad en las decisiones de política monetaria, sumado a diferentes criterios de independencia y accountability sobre las llamadas decisiones con efectos económicos indirectos, llevaron al BVerfG a declarar que la actuación de la UE había excedido las competencias transferidas de un modo «estructuralmente significativo». Con un ojo puesto en el Pandemic Emergency Purchase Programme (PEPP)

1 Profesor de Derecho Internacional Público en la Universidad Nacional de Educación a Distancia. 
acepta, aunque con reparos, los requisitos que sobre el PSPP se imponen para evitar la financiación monetaria prohibida por el art. 123 TFUE. Como la sentencia no ha tenido efectos prácticos inmediatos sobre el PSPP, el daño al principio de primacía no sería suficiente como para iniciar un procedimiento de incumplimiento. Este artículo analiza la doctrina ultra vires del BVerfG (II), la influencia monetarista en el diseño del BCE (III), cómo entiende el TJUE el control sobre su mandato (IV) y sus diferencias con el BVerfG (V), la afectación al principio de primacía (VI), y cierra con unas conclusiones con las posibles contribuciones de este «diálogo» para la mejora de la legitimación democrática de la política monetaria.

\title{
Palabras clave
}

Tribunal Constitucional Alemán; control ultra vires; política monetaria europea; mandato del BCE; legitimidad democrática; independencia del BCE; PSPP; adquisición de deuda pública; proporcionalidad strictu sensu; transparencia; accountability; financiación monetaria; principio de primacía.

\section{THE PUBLIC SECTOR PURCHASE PROGRAMME (PSPP) FACE TO ECJ AND GERMAN FEDERAL CONSTITUTIONAL COURT CASELAW: BACKGROUND AND CONSEQUENCES OF THE BVerfG DECISION OF 5 MAY 2020 (2 BvR 859/15)}

\begin{abstract}
On 5 May 2020, the German Federal Constitutional Court (BVerfG) declared the ECB's Public Sector Purchase Programme (PSPP), and hence ECJ's Weiss preliminary ruling that had validated it, as ultra vires. It is a no return point in the so-called dialogue between both courts. Disagreements concerned ECB's mandate (art. 127 TFEU), particularly how the principle of proportionality should be applied on monetary policy decisions, and different approaches on ECB's independency and accountability on those decisions with indirect economic effects. All together led the BVerfG to declare that the EU had had exceeded its competences in a "structurally significant» manner. Keeping the Pandemic Emergency Purchase Programme (PEPP) in mind the BVefG accepted, with objections, the conditions imposed to the PSPP for fulfilling art. $123 \mathrm{TFEU}$ (prohibition of monetary financing). Since the decision actually has had no direct effects on the programme in practice, damages on the principle of primacy of EU law would not deserve the initiation of an infringement procedure. This article starts analysing the BVerfG ultra vires doctrine (section II), the influence of monetarism in the design of the ECB mandate (III), how the ECJ understands the judicial control on it (IV) face to the positions of the BVerfG (V), the effects of the decision on the principle of primacy (VI) and it closes with some concluding remarks on the contributions of this «dialogue» for improving democratic legitimacy of the monetary policy.
\end{abstract}




\section{Keywords}

German Constitutional Court; ultra vires control; European monetary policy; ECB mandate; democratic legitimacy; ECB independence; PSPP; public debt purchase; proportionality strictu sensu; transparency; accountability; monetary financing; principle of primacy.

\section{LE PUBLIC SECTOR PURCHASE PROGRAMME (PSPP) A LA LUMIERE DES JURISPRUDENCES DE LA CJUE ET DE LA COUR CONSTITUTIONNELLE FEDERALE ALLEMANDE: CONTEXTE ET CONSEQUENCES DE L'ARRET DU 5 MAI 2020 DE BVefG (2 BvR 859/15)}

\section{Résumé}

L'arrêt du 5 mai 2020 de la Cour Constitutionnelle Fédérale Allemande qui déclare ultra vires le Public Sector Purchase Programme (PSPP) de la BCE, et en conséquence aussi l'arrêt Weiss de la CJUE que l'avait validé, constitue un moment critique du dialogue entre les deux tribunaux. Les désaccords comprennent les limites du mandat de la BCE (art. 127 TFUE), en particulier sur comment on doit d'appliquer le principe de proportionnalité aux décisions de politique monétaire, et les critères d'independence et accountability applicables aux mesures avec des effets économiques indirects. Tout ceci a emmené à la Cour Constitutionnelle Allemande à déclarer que l'actuation de l'UE avait surpassé les compétences déléguées d'un façon «structurellement significatif». Avec un oil sur le Pandemic Emergency Purchase Programme (PEPP) elle approuve, avec des objections, les conditionnes imposées sur le PSPP pour accomplir la prohibition de financement monétaire de l'art. 123 TFUE. Etant donné que la décision n'a pas eu des conséquences pratiques directes sur le PSPP, le dommage au principe de primauté ne justifierait pas l'ouverture d'une enquête envisagée un recours en manquement. Cet article analyse la doctrine ultra vires de la Cour Constitutionnelle Allemande (II), l'influence monétariste sur l'architecture de la BCE (III), le control du mandat de la BCE selon la CJUE (IV) et leurs différences avec la Cour Constitutionnelle Allemande (V), l'affectation au principe de primauté (VI) et il conclue avec des réflexions finales sur les conséquences du ce "dialogue» pour améliorer la légitimation démocratique de la politique monétaire.

\section{Mots clés}

Cour Constitutionnelle Allemande, control ultra vires, politique monétaire européenne, mandat de la BCE, Independence de la BCE, PSPP, rachat de dette publique, proportionnalité strictu sensu, transparence, accountability, financement monétaire, principe de primauté. 


\section{SUMARIO}

I. INTRODUCCIÓN. II. DEMOCRACIA Y CONTROL ULTRA VIRES: LA TEORÍA DEL BVERFG. III. MONETARISMO, INDEPENDENCIA Y LEGITIMIDAD DEL BCE. IV. CONTROL JUDICIAL DE LA POLÍTICA MONETARIA POR EL TJUE: GAUWEILER Y WEISS: 1. El programa OMT y la cuestión prejudicial Gauweiler. 2. El PSPP y la cuestión prejudicial Weiss. V. LA POLÍTICA MONETARIA EUROPEA SEGÚN EL BVERFG, DE OMT A PSPP, Y LAS REPERCUSIONES PARA EL PEPP: 1. El mandato, la independencia y la intensidad del control. 2. Proporcionalidad strictu sensu como núcleo esencial del control ultra vires. 3. La financiación monetaria como verdadera línea roja de la política monetaria. VI. PRIMACÍA Y EFECTIVIDAD DE LAS DECISIONES JUDICIALES EN MATERIA DE UEM. VII. CONCLUSIONES. BIBLIOGRAFÍA.

\section{INTRODUCCIÓN}

La Unión Europea (UE), como toda organización internacional con competencias atribuidas y con un tribunal de justicia que interpreta su derecho originario y controla la legalidad sus actos, se enfrenta tarde o temprano al principio kompetenz-kompetenz. Desde una perspectiva de la UE, es natural que se prime el principio de efectividad, y por lo tanto se tienda a interpretar «activamente» sus competencias de un modo que le permitan alcanzar sus objetivos, siempre bajo el control de los principios de proporcionalidad y subsidiaridad. En cambio, los tribunales constitucionales realizan un análisis más restrictivo con vistas a reestablecer el equilibrio de competencias entre la UE y los Estados. Y si estos son especialmente activos, como el Bundesverfassungsgerichts (BVerfG) o Tribunal Constitucional Federal Alemán (TCFA), bajo la amenaza de declarar la acción de la UE como ultra vires de las competencias transferidas y, por lo tanto, inconstitucional ab intra.

El fundamento utilizado por el BVerfG para admitir a trámite los recursos y justificar el escrutinio constitucional de los actos ultra vires de la Unión es la falta de legitimidad democrática de aquellas decisiones que excedan las competencias trasferidas, aclarando que algunas, dado el estado de desarrollo de la unión (en términos de calidad democrática), serían intransferibles, entre ellas, la política fiscal. 
Aunque a simple vista pareciese un enfrentamiento entre la UE y sus Estados miembros (o entre TJUE y BVerfG), la realidad es más compleja. El equilibrio entre las competencias de la UE y la autonomía de los Estados miembros excede el supuesto "excesivo activismo» del TJUE para interpretar expansivamente las competencias de la Unión. Los Estados miembros participan también en este proceso: ampliando las competencias en cada reforma, apoyando en el seno del Consejo derecho derivado que limitarán las suyas, o refrendando agendas pro-europeas a la hora de participar en el proceso de elección de otras instituciones, como la Comisión. El competence creep (Craig, 2011: 12) incluiría, además de las cláusulas de flexibilización competencial (principalmente el art. 114 TFUE), la integración "paralela» (tratados inter se) y la gobernanza económica (y en particular los memoranda de entendimiento de los sucesivos rescates) que, aunque nunca hayan sido incluidos en el argumentario del BVerfG, también despiertan dudas sobre su legitimidad democrática (Garben, 2019).

Nos parece interesante, por lo tanto, desligar el control ultra vires del elemento identitario y relacionarlo más con el argumentario democrático. Así, nos planteamos como pregunta de investigación si la jurisprudencia reciente del BVerfG, en diálogo con el TJUE, puede considerarse una contribución al debate sobre la democratización de la política monetaria y, en general, sobre la gobernanza económica de la Unión.

En primer lugar, se tratará la teoría del control ultra vires del BVerfG (II), luego se analizará cómo ha influido el monetarismo en el diseño de la política monetaria y en particular en la conformación del mandato e independencia del BCE, y por qué se consideraba esta última una excepción al principio de legitimidad democrática (III). Posteriormente se verá cómo la jurisprudencia del TJUE (Gauweiler ${ }^{2}$ y Weiss $^{3}$ ) ha tenido que justificar en base a ese marco legal obsoleto medidas del BCE que claramente ya se alejaban del esquema que lo vio nacer (IV). Estas diferencias, después de un corto entendimiento de la sentencia $O M T^{4}$ sobre el nunca implementado Outright Monetary Transactions (OMT), serán irreconciliables en la decisión $P S P P^{5}$. A pesar de la conclusión final, el BVerfG sí hace concesiones, aceptando efectos económicos indirectos

\footnotetext{
Sentencia de 16 de junio de 2015, Gauweiler, C-62/14, EU:C:2015:400.

3 Sentencia de 11 de diciembre de 2018, Weiss, C-493/17, EU:C:2018:1000.

4 Sentencia del TCFA del 21 de junio de 2016, OMT, 2 BvR 2728/13, DE:BVerfG:2016:rs20160621.2bvr272813. Disponible en inglés en: https://bit.ly/3cfvk95.

5 Sentencia del TCFA del 5 de mayo de 2020, PSPP, 2 BvR 859/15, DE:BVerfG:2020:rs20200505.2bvr085915. Disponible en inglés en: https://bit.ly/3rzgxfO. Para un comentario general véanse Bursi (2020) y Galetta y Ziller (2020).
} 
(y por lo tanto rechazando el monetarismo puro) en la política monetaria, aunque sometiéndolo a un control más estricto (V.1). Y aquí es donde probablemente actúa de un modo desleal con el TJUE, desarrollando un control de proporcionalidad strictu sensu que nunca mencionó en sus preguntas en la cuestión prejudicial (V.2). Sin perjuicio de ello, el verdadero problema a futuro está oculto en las condiciones, impuestas por el TJUE y que el BVerfG acepta, para evitar incumplir la obligación de financiación monetaria (V.3). Como era de esperar de una desobediencia a una sentencia del TJUE, hay un cuestionamiento al principio de primacía, aunque al someter sus efectos a una condición que, en la práctica, ha hecho que no tenga repercusiones directas sobre el Public Sector Purchase Programme (PSPP) (VI). Como es habitual, se cierra con unas conclusiones en donde se intenta responder a la pregunta de investigación planteada.

\section{DEMOCRACIA Y CONTROL ULTRA VIRES: LA TEORÍA DEL BVERFG}

Si bien el diálogo que mantuvieron el BVerfG y el TJCE en la saga Solange ${ }^{6}$ favoreció la creación de un espacio europeo de derechos fundamentales (González Pascual, 2010: 124-145), la cesión de la política monetaria con el Tratado de Unión Europea llevaría el control constitucional del derecho europeo a otro nivel.

En la sentencia Maastricht el BVerfG se declaró competente para analizar un recurso de amparo de varios ciudadanos alemanes que objetaban la transferencia de soberanía a la Unión de las facultades que hasta entonces tenía el Bundesbank en materia de política monetaria, fundándose en que estas no estaban suficientemente resguardadas por su inacabada estructura democrática. Con una interpretación flexible el BVerfG aceptó que el derecho al voto del art. 38 de la Constitución alemana o Ley Fundamental (Grundgesetz, en adelante) no era solo un derecho formal a elegir un parlamento sino un derecho material de todo ciudadano alemán para exigir el efectivo ejercicio de las competencias del mismo ${ }^{8}$. Como la UE carecía de kompetenz-kompetenz,

6 Sentencia del TCFA de 29 de mayo de 1974, Solange I, 2 BvL 52/71. Disponible en inglés en: https://bit.ly/3t8U8ql. Sentencia del Tribunal Constitucional Federal Alemán de 22 de octubre de 1986, Solange II, 2 BvR 197/83. Disponible en inglés en: https://bit.ly/3qweOXi.

7 Sentencia del TCFA de 12 de octubre de 1993, Maastricht, 2 BvR 2134/92 y 2159/92. Disponible en inglés en: https://bit.ly/30rv1Tm. Para un comentario véase Stein (1994).

8 Ibid., apdo. 102. 
y de estructuras democráticas suficientes que pudiesen legitimarla, toda extralimitación en las competencias transferidas por el Bundestag, que a su vez se legitima por el voto de los ciudadanos, obligarían a declararlas no democráticas porque violaban su derecho al voto y, por lo tanto, eran inconstitucionales? Para los casos dudosos, el alcance de las competencias transferidas estaría limitado por el principio de subsidiariedad y proporcionalidad, ambos bajo el control del TJUE, aunque revisable por el $\mathrm{BVerfG}^{10}$.

$\mathrm{Al}$ analizar la calidad democrática de la transferencia de la competencia monetaria, aunque reconocía que esta era una política esencial ${ }^{11}$, consideraba que el traspaso mantenía los estándares alemanes ya que la Unión Monetaria tenía como prioridad esencial mantener la estabilidad de precios ${ }^{12}$. Además, la independencia del BCE, equivalente a la del Bundesbank, era una modificación de los derechos [democráticos] de los ciudadanos, justificada porque esta era la mejor garantía para mantener el valor de la moneda ${ }^{13}$. Es decir, el mandato del BCE de mantener la estabilidad de precios era el fundamento y la razón última por la cual se aceptaba la transferencia y se justificaba la no realización, en abstracto, de un control legitimidad democrática. Además, se asumía que la Unión iría mejorando la calidad democrática de sus instituciones, en particular en relación con la política monetaria ${ }^{14}$.

En la sentencia $L i s b o a^{15}$, el BVerfG retoma el argumento del déficit democrático de las instituciones de la Unión para aumentar la intensidad de control ultra vires ${ }^{16}$. Luego de analizar la estructura normativa e institucional de la Unión, el TCFA parece entender que su capacidad de absorción competencial, en términos de legitimidad democrática, está cerca de su máximo, al

$9 \quad$ Ibid., apdos. 62-63.

10 Ibid., apdo. 155. Esta capacidad de revisión ya había sido adelantada en la Sentencia del TCFA de 8 de abril de 1987, TJCE como juez legal, 2 BvR 687/85.

11 Maastricht, apdo. 153.

12 Ibid., apdo. 138.

13 Ibid., apdo. 154.

14 Ibid., apdo. 106. Para un comentario sobre la visión de otros tribunales constitucionales en relación con el control del desarrollo de la política económica y monetaria, véase Capeta (2018).

15 Sentencia del TCFA de 30 de junio de 2009. Lisboa, 2 BvE 2/08, 5/08, 1010/08, 1022/08, 1259/08 y 182/09. Disponible en castellano en: https://bit.ly/3cbWQVa.

16 La doctrina española en general fue bastante crítica con la sentencia (Martín y Pérez de Nanclares, 2011: 100), que fue calificada de «tremendista» (Bobes Sánchez 2010: 163), e incluso de un "tono general de claro escepticismo con respecto al proceso de integración» (Castillo de la Torre 2009: 1008). Este último, en página 997 y ss., recopila otros comentarios críticos similares de la doctrina no española. 
menos a la luz de la capacidad de cesión que tiene la constitución alemana. Para poder ampliarlo habría que reformar todo el sistema de reparto competencial entre la Unión y los Estados, hacia un modelo de federación europea. Mientras tanto, todo intento de ampliación competencial, sea de iure o de facto, debía ser controlado para impedir una reforma indirecta (e inconstitucional) de la Grundgezetz (Castillo de la Torre 2009: 1009) aunque solo se aplicaría a transgresiones «obvias» ${ }^{17}$. Para distinguir cuáles eran, aclara que habría cinco áreas sensibles ${ }^{18}$, núcleo duro de soberanía (Thym 2009: 1797) o «identidad constitucional», cuyo control debía ser más celoso ${ }^{19}$. De otro modo, se podría afectar no solo un derecho particular de los ciudadanos, sino aquellos contenidos en la «eternity clause» del art. 79 de la Grundgezetz que concretan la propia identidad del Estado (esencialmente como Sozialstaat), y con él, el derecho de autodeterminación del pueblo alemán, que no sería modificable ${ }^{20}$. Entre ellas se encontraban las decisiones fundamentales en materia fiscal y la autonomía presupuestaria.

Hay que destacar que en la sentencia Lisboa no se objeta la cesión de la política monetaria ${ }^{21}$, ni se menciona al $\mathrm{BCE}$, en particular, como una institución europea con déficit democrático. Respecto a las restricciones que tendría la UE para introducirse en estas áreas sensibles, en general se refiere a una participación real y efectiva de los parlamentos nacionales ${ }^{22}$. En particular, sobre la «autonomía presupuestaria», se afirma que:

The German Bundestag must decide, in an accountable manner vis-à-vis the people, on the total amount of the burdens placed on citizens. The same applies correspondingly to essential state expenditure. In this area, the responsibility concerning social policy in particular is subject to the democratic decision-making process, which citizens want to influence through free and equal elections. Budget sovereignty is where political decisions are planned to combine economic burdens with benefits granted by the state ${ }^{23}$.

17 Lisboa, apdo. 240.

18 Ibid., apdo. 252. Estas áreas serían: derecho civil y penal, seguridad interior y exterior del estado y el uso de la fuerza, fiscalidad y autonomía presupuestaria, seguridad social y políticas sociales, política comercial común, sistemas educativo y cultura. Se trataría, sin embargo, de un listado ejemplificativo (Pernice, 2011).

19 Ibid., apdos. 241 y 340

20 Ibid., apdos. 181-183.

21 Más bien la acepta en su apdo. 248.

22 Ibid., apdo. 210.

23 Ibid., apdo. 256. 
La construcción teórica del BVerfG sobre el control ultra vires se matizó y limitó en la práctica. La relajación vino, en primer lugar, por la aceptación de la posibilidad de plantear cuestión prejudicial ${ }^{24}$, cosa que ocurrió en el asunto Gauweiler. Pero incluso antes que esto, en Honeywell ${ }^{5}$, el TCFA tuvo la oportunidad de aplicar en un caso concreto el control ultra vires de Lisboa. Para esto matizó que para que haya inconstitucionalidad hacía falta que la UE hubiera cometido una «violación suficientemente caracterizada ${ }^{26}$ que, sin lugar a dudas, produjese un cambio significativo y estructural de competencias en detrimento de los Estados (requisito de fondo) ${ }^{27}$ y que previamente se hubiese plantado una cuestión prejudicial (requisito de forma) ${ }^{28}$. Este último servía para demostrar su cooperación sincera y mutuo respeto. Además, se otorgaba al TJUE el «derecho a tolerarle un error» ${ }^{29}$. En el caso concreto, si bien entendía que el TJUE había errado en Mangold $^{30}$, una sentencia aislada no era una violación suficientemente caracterizada, por lo que ni siquiera vio necesario plantear cuestión prejudicial. De ello se desprende que el BVergG plantearía una cuestión prejudicial, en un contexto de control ultra vires, solo si tuviese indicios de que pudiese habido una violación de este tipo, lo que transmuta el control ultra vires en un control de la racionalidad del pronunciamiento del TJUE (Azpitarte Sánchez, 2016).

Como analizaremos en el punto IV, al tratar la jurisprudencia sobre política monetaria, en su primera cuestión prejudicial se hace una última matización. Ante supuestos dudosos, en particular sobre medidas que afectan competencias de la Unión con otras que en principio no lo son o cuando existen dudas sobre el control de democracia que pueden ejercer los parlamentos nacionales, el principio de proporcionalidad sería esencial para

24 Sentencia del TCFA de 2 de marzo de 2010, Data Retention, 1 BvR 256/08, 1 BvR 263/08 y 1 BvR 586/08. DE:BVerfG:2010:rs20100302.1bvr025608.

25 Sentencia del Tribunal Constitucional Federal Alemán de 6 de julio de 2010, Honeywell, 2 BVerfGE 2661/06. DE:BVerfG:2010:rs20100706.2bvr266106. Para un comentario véanse Corti Varela et al. (2011) y Payandeh (2011).

26 Ibid., apdo. 304. En la sentencia Lisboa ya hablaba de "transgresiones obvias» (apdo. 240). Según el juez Landau, en su voto particular, esta se produce «each expanding interpretation of the Treaties which is tantamount to a non-permissible autonomous amendment of the Treaty» (apdo. 101).

27 Sentencia Honeywell, apdo. 61.

28 Ibid., apdo. 60.

29 Ibid., apdo. 66.

30 Sentencia de 22 de noviembre de 2005, Mangold, C-144/04. EU:C:2005:709. 
justificar que efectivamente no se ha violado el principio de atribución de competencias $^{31}$. Este elemento será fundamental en PSPP.

\section{MONETARISMO, INDEPENDENCIA Y LEGITIMIDAD DEL BCE}

El monetarismo fue una teoría económica predominante a partir de la crisis del petróleo de los años setenta, y popularizada por Milton Friedman, que criticaba abiertamente el keynesismo imperante con el fin de la Segunda Guerra Mundial. Según Friedman (1968) la función primordial de la política monetaria era garantizar la estabilidad de precios. Para evitar que los poderes políticos estimulasen artificialmente la economía con emisión monetaria más allá de su potencial, y con ella generasen inflación, era necesario que la política monetaria estuviese a cargo de una autoridad independiente guiada por criterios exclusivamente técnicos. La emisión se modularía a través de la fijación del tipo de interés, un criterio eminentemente técnico que se ajustaba perfectamente a la concepción econométrica de la economía.

Desde tiempos de Ricardo la principal herramienta de política monetaria era la fijación de tipos de interés. Esta tarea se ajustaba al criterio de modulación técnica. Por ello en el monetarismo el mandato de los bancos centrales se limitó a subir los tipos cuando la inflación se aceleraba, aunque produjese recesión y desempleo, y bajarla cuando esta se acercaba a su objetivo a largo plazo. Si bien se dañaba la economía a corto plazo, produciendo perjuicio social, se contaba con que esta (y el empleo) se recuperarían pronto, y este daño sería menor que una inflación crónica por la creación de expectativas inflacionarias. Como estos ciclos eran más largos que los políticos, las medidas impopulares no verían sus efectos positivos hasta el siguiente Gobierno, por lo que había un claro desincentivo para aplicarlas y, por ello, era necesario dejarlas en manos de una autoridad técnica e independiente (Goodhart y Jensen, 2015). El hecho que los bancos centrales prácticamente pudiesen utilizar solo una herramienta, y con un objetivo en concreto, justificaba su gran independencia del control de los poderes democráticos.

Esta teoría fue académicamente aceptada en los años setenta y ampliamente aplicada en los ochenta. Incluso los estudios econométricos parecían demostrar que los países donde los bancos centrales contaban con mayor independencia (Bundesbank y Banco Central Suizo) lograban contener mejor la inflación (Eich y Tooze, 2016). La otra parte de la historia es que las alzas en los tipos afectaban no solo a la actividad privada, sino también a las finanzas

31 Fundándose en jurisprudencia del TJUE, aunque desde su perspectiva, sentencia OMT apdos. 179-180. 
públicas, en especial cuando se partía de un alto endeudamiento, y esto era más acuciante cuando la deuda pública estaba denominada en una moneda diferente. Las subidas de tipos que realizó la Reserva Federal estadounidense, hasta el $20 \%$ a mediados de los ochenta, redujo drásticamente la inflación en los EE.UU., pero hizo prácticamente impagable la deuda latinoamericana denominada en dólares, conduciendo a un ciclo de inestabilidad conocido como «crisis de la deuda latinoamericana» o «década perdida» (Ocampo et.al., 2014). La política monetaria tenía lazos importantes no solo con la económica sino también con la sostenibilidad de la deuda pública.

La UEM se diseñó en el contexto del máximo apogeo del monetarismo (McNamara, 1998), y el mandato (Herdegen, 1998) e independencia (Lastra, 1992: 482-496) que recibió el BCE es claro ejemplo de ello. «El objetivo principal del Sistema Europeo de Bancos Centrales [...] será mantener la estabilidad de precios» [arts. 127 y art. 282 (2) TFEU y art. 2 Estatuto SEBC y BCE]. Para ello goza de una gran independencia de cualquier otra autoridad europea o nacional [arts. 130, 282(3) TFUE]. Semejante autonomía de autoridades no electas se justificaba, en términos de legitimidad democrática, en el paradigma monetarista (de Boer y van't Klooster, 2020). Para reforzar dicha independencia, y reducir aún más su discrecionalidad en el ejercicio de la política monetaria, se le prohibía realizar cualquier tipo de financiación monetaria de carácter público (art. 123 TFUE). El carácter técnico y restringido de sus objetivos haría que la rendición de cuentas (accountability) del BCE se limitase a controlar que no se extralimitase de su mandato (Lastra, 1992; Issing, 1999; Magnette, 2000; BCE, 2002; Fromage et.al., 2019; en contra Curtin, 2017). Y al carecer de mecanismos de control político, el control solo podría ser judicial (Lastra, 1992: 500; Scheller, 2006; Amtenbrink 2018: 940).

\section{CONTROL JUDICIAL DE LA POLÍTICA MONETARIA POR EL TJUE: GAUWEILER Y WEISS}

El consenso monetarista entró en crisis con la llegada del siglo XXI. La década anterior había sido tranquila en términos inflacionarios, en gran medida por los efectos deflacionarios de la apertura comercial hacia Oriente, y también por la eliminación de la presión por subida de salarios, por las políticas neoliberales del consenso de Washington, que se generalizaron a partir de la caída del muro de Berlín. La explosión de la burbuja «punto com» (1997-2001) llevó los tipos de referencia a niveles históricamente bajos sin que esto generase presiones inflacionarias, y así se han mantenido desde entonces, reduciendo la capacidad de influencia de los bancos centrales sobre la política monetaria por los medios tradicionales. 
Cuando llegó la crisis financiera de 2008, que en la Eurozona devino en una crisis de deuda, para muchos, otra burbuja especulativa alimentada por tipos excesivamente bajos durante mucho tiempo, el BCE se encontraba ante un doble desafío. Por una parte, garantizar la liquidez del sistema, como en cualquier crisis financiera, problema que compartía con el resto de bancos centrales de países industrializados; y por la otra, mantener unido al euro, ya que los riesgos de ruptura o, incluso, su propia supervivencia, estaba en entredicho.

\section{EL PROGRAMA OMT Y LA CUESTIÓN PREJUDICIAL GAUWEILER}

El segundo desafío era, probablemente, el más acuciante. A falta de un presupuesto europeo con la capacidad suficiente como para tomar medidas macroeconómicas anticíclicas, y las limitaciones tanto de tamaño como operacionales de los sucesivos fondos de rescate para-comunitarios (Fondo Europeo de Estabilidad Financiera, Mecanismo Europeo de Estabilidad Financiera, EFSM en sus siglas en inglés, y posteriormente el Mecanismo Europeo de Estabilidad, MEDE) el 23 de julio de 2012 el presidente del BCE pronunció su conocido "whatever it takes" ${ }^{32}$ para salvar el euro. Las medidas «no convencionales» que desde entonces se adoptaron se alejaban claramente del paradigma monetarista. La primera de importancia fue anunciar, a través de un comunicado de prensa ${ }^{33}$, el programa OMT (que textualmente significa «operaciones monetarias sin restricciones») que pretendía restaurar la transmisión normal de los estímulos monetarios y salvaguardar «la unidad de la política monetaria». En la práctica, se intentaba reducir las diferencias de tipos de interés de la deuda pública de ciertos países, a través de la compra directa por parte del BCE en los mercados secundarios, siempre que los Estados se mantuviesen en los programas de ajustes económicos por los compromisos asumidos vía EFSM/MEDE. Es decir, el OMT completaba la ayuda del EFSM/MEDE bajo su misma condicionalidad (Tuori y Touri, 2014:186187). El programa OMT fue aprobado por todos los miembros del consejo del BCE, excepto el voto negativo del representante del Bundesbank ${ }^{34}$. Las intervenciones del $\mathrm{BCE}$, sin embargo, no fueron necesarias ya que la liquidez

32 Discurso de Mario Draghi, presidente del Banco Central Europeo en la Global Investment Conference, Londres, 26 de julio de 2012. Disponible en: https://bit.ly/38FDC9x.

33 Nota de Prensa del Banco Central Europeo del 6 de septiembre de 2012 «Technical features of Outright Monetary Transactions». Disponible en: https://bit.ly/30qSMe6.

34 Entrevista del 4 de diciembre de 2019 (y publicada el 16 de diciembre) del periodista Jean Quatremer (Liberation) con Benoît Cœuré, miembro del Consejo Ejecutivo del BCE. Disponible en: https://bit.ly/30q1vNx. 
y la tranquilidad en los mercados de deuda pública, volvieron por el solo hecho de que este pudiese articularse. Así, el programa se habría convertido en una suerte de «seguro» que no fue necesario utilizar ${ }^{35}$.

Esto no impidió que, aplicando el marco teórico planteado en la sección II, el BVerfG diese trámite a una demanda liderada por el parlamentario de la CSU, y euroescéptico, Peter Gauweiler, contra el Bundesbank. Siguiendo los requisitos procedimentales autoimpuestos en la sentencia Honeywell, el BVerfG planteó su primera cuestión prejudicial convencido de que las decisiones que había adoptado el BCE y el SEBC (entre los que estaba el Bundesbank) para poner en marcha el programa OMT constituían una violación suficientemente caracterizada de las competencias monetarias transferidas y, por lo tanto, ultra vires ${ }^{36}$. Argumenta que el programa OMT violaba la soberanía fiscal del parlamento alemán y llevaría necesariamente a una redistribución de responsabilidades fiscales entre los Estados miembros ${ }^{37}$. Poco antes, en la decisión $E F S M^{\beta 8}$, el BVerfG había afirmado que el Bundestag no podría transferir responsabilidades presupuestarias ilimitadas a nivel europeo ${ }^{39}$. $\mathrm{Y}$ en su decisión $M E D E^{40}$, que solo el Bundestag, contando con toda la información necesaria, podría garantizar la legitimidad democrática de los compromisos fiscales.

En respuesta a la petición, la sentencia del TJUE Gauweiler ${ }^{41}$ elude la tentación de declarar inadmisible la cuestión ${ }^{42}$ y avanza sobre el fondo. Primero

35 Discurso de Benoît Couré, miembro del Consejo Ejecutivo del BCE, en la conferencia «The ECB and its OMT programme» organizada por el Centre for Economic Policy Research, el German Institute for Economic Research y el KfW Bankengruppe. Berlín, 2 de Septembre de 2013. Disponible en: https://bit.ly/38ntvFT.

36 Sentencia $O M T$, apdos. 39-43.

37 Sentencia $O M T$, apdos. 41 y 43.

38 Sentencia del TCFA de 7 de septiembre de 2011, EFSM, 2 BvR 987/10,DE:BVerfG:2011:rs20110907.2bvr098710. Disponible en inglés en: https://bit.ly/3quJSXu. Para un comentario véase López Castillo (2011).

39 Ibid., aptdos. 179-180.

40 Sentencia del TCFA de 12 de septiembre de 2012, MEDE, 2 BvR 1390/12, DE:BVerfG:2012:rs20120912.2bvr139012. Para un comentario véase Schneider (2013).

41 Para comentarios de la sentencia: Fabbrini (2015), Craig y Markakis (2016), Adamski (2015) y Martucci (2015).

42 Dudas sobre la sumisión del órgano requirente a la decisión del TJUE (párr. 16), carácter hipotético de la consulta (Gauweiler, apdo. 25) y uso de un procedimiento incorrecto (Gauweiler, apdo 29). Recuérdese que una demanda similar contra el OMT había sido declarada inadmisible por el Tribunal General, y desestimada su apelación ante el TJUE. Véase el Auto del Tribunal General de 10 de diciembre de 2013, von 
descarta que el programa OMT, analizando sus objetivos («salvaguardar tanto la adecuada transmisión de la política monetaria como la unicidad de dicha política») ${ }^{43}$ e instrumentos ("operaciones monetarias de compraventa de títulos en los mercados secundarios de deuda soberana») ${ }^{44}$, exceda los poderes del $\mathrm{BCE}$ en materia de política monetaria ${ }^{45}$. Aclara que las repercusiones en materia de política económica («estabilidad de la zona euro») no serían incompatibles con el mandato del $\mathrm{BCE}^{46}$. El programa no constituiría una violación al art. 123 TFUE, que prohíbe únicamente las compras en mercado primarios, idea que se refuerza en el hecho de que en el propio estatuto del SEBC se autorizan las adquisiciones de deuda en los mercados secundarios, sumado a que la condicionalidad impuesta a través del MEDE, todo lo cual reforzarían su compatibilidad ${ }^{47}$. Es más, si a través del OMT se reforzasen, incidentalmente, los objetivos de política económica de dichos programas de ajuste, esto no convertiría al mismo en una medida de política económica. Y los posibles efectos indirectos, estarían cubiertos por el hecho de que el BCE, además de su objetivo de estabilidad de precios, debe apoyar las políticas económicas generales de la unión ${ }^{48}$.

$\mathrm{Al}$ concluirse que las medidas cabían dentro de las competencias del BCE, analiza posteriormente su proporcionalidad. Siguiendo al abogado general (AG) Cruz Villalón, otorga al BCE un amplio margen de discrecionalidad en la toma de decisiones de naturaleza técnica que incluyen previsiones y análisis complejos ${ }^{49}$. Solo se realizaría un control de garantías procesales que incluiría la obligación, por parte del $\mathrm{BCE}$, de examinar de modo detallado e imparcial todos los elementos relevantes y dar argumentos adecuados sobre las razones de sus decisiones ${ }^{50}$. En relación con el test de necesidad, como el programa OMT nunca fue implementado en la práctica, y estaba condicionado a la realización de programas de ajustes económicos, además de poder modularse según la situación del mercado; entendía que no iba manifiestamente más allá de lo necesario para alcanzar sus objetivos ${ }^{51}$. En segundo lugar, descarta una violación a la prohibición de financiación monetaria del art. 123

Storch,T-492/12, EU:T:2013:702, confirmado por Auto del Tribunal de Justicia de 29 de abril de 2015, von Storch, C-64/14 P, EU:C:2015:300.

Sentencia Gauweiler, apdo. 47.

Ibid., apdo. 53.

Ibid., apdos. 46-59.

Ibid., apdo. 51.

Ibid., apdos. 54 y 57.

Ibid., apdos. 58 y 59

Ibid., apdo. 68.

Ibid., apdo. 69.

Ibid., apdo. 81. 
TFUE. Recordando los argumentos de Pringle ${ }^{52}$, descarta que el programa OMT pretendiera desarrollar una política presupuestaria ${ }^{53}$ primero porque era compra en mercados secundarios, supeditada a condiciones de consolidación fiscal, y segundo, porque las eventuales pérdidas habrían sido muy inferiores a las que se producirían en caso de que se rompiese la unión monetaria ${ }^{54}$.

La sentencia del BVerfG que debía implementar Gauweiler $\left(O M T^{55}\right)$ aunque manteniendo algunas «serias objeciones» ${ }^{56}$, retomó la distinción del TJUE entre adopción y condiciones de implementación, reafirmando que, si bien el programa era en su forma original ultra vires, con los requisitos impuestos por el TJUE (condiciones de implementación) había dejado de serlo ${ }^{57}$, congratulándose de que gracias a la cuestión prejudicial planteada el derecho de la Unión volvía a la senda de la legalidad ${ }^{58}$, todo lo cual recordaba el espíritu de diálogo de la saga Solange. La decisión fue calificada por algunos como "saving face» (Pliakos y Anagnostaras, 2017), ya que las condiciones de implementación no fueron «impuestas» por el TJUE en la cuestión prejudicial, sino que ya existían en los comunicados de prensa del BCE, y esta solo las recogería ${ }^{59}$. Sin embargo, la cuestión de fondo, es decir cómo entendía cada tribunal el mandato de la política monetaria y el alcance del control de proporcionalidad en aquellas zonas grises, quedaba sin resolverse.

\section{EL PSPP Y LA CUESTIÓN PREJUDICIAL WEISS}

Vuelta la liquidez a los mercados y, por lo tanto, superado el riesgo de ruptura del euro, el BCE volvió centrarse en la estabilidad de precios. Ante los persistentes riesgos deflacionarios, el BCE continuó con su política heterodoxa de expansión monetaria en sintonía con otros bancos centrales (Andrade et. al., 2016). Primero con una financiación extremadamente blanda para bancos

\footnotetext{
Sentencia de 27 de noviembre de 2012, Pringle, C-370/12. EU:C:2012:756.

Sentencia Gauweiler, apdo. 111.

4 Ibid., apdos. 113, 115 y 125.

55 Para un comentario en castellano véase Sáinz de Vicuña y Barroso (2016).

56 Sentencia $O M T$, apdos. 181 y ss.

57 Sentencia $O M T$, apdo. 177.

58 Sentencia OMT, apdo. 190.

59 Incluso la oscura condición, impuesta junto con otras cinco al Bundesbank para participar en el programa (OMT, apdo. 206), de que el monto de la intervención esté limitado desde un principio no es nueva ya que ese límite no es un límite cuantitativo sino relativo (hasta que sea efectiva para reestablecer el equilibrio monetario) con lo cual sería una «nueva» condición aparente. Pliakos y Anagnostaras (2017: 222).
} 
de la eurozona ${ }^{60} \mathrm{y}$, ante la poca repercusión, en 2014 inició un ambicioso Programa de Compra de Activos (Asset Purchase Programme o APP en inglés) para la adquisición de deuda corporativa ${ }^{61}$, deuda pública (PSPP) $)^{62}$, valores respaldados por activos ${ }^{63}$ y bonos garantizados ${ }^{64}$. En 2020 , como consecuencia de los efectos económicos de la pandemia de la COVID-19, el BCE creó un nuevo Programa de Compras de Emergencia Pandémica (Pandemic Emergency Purchase Program o PEPP en inglés) que sigue criterios similares al APP ${ }^{65}$.

60 Decisión (UE) 2014/34 del Banco Central Europeo de 29 de julio de 2014, sobre las medidas relativas a las operaciones de financiación a plazo más largo con objetivo específico (DO L 258 de 29.8.2014, p. 11).

Decisión (UE) 2016/810 del Banco Central Europeo de 28 de abril de 2016, sobre la segunda serie de operaciones de financiación a plazo más largo con objetivo específico (DO L 132 de 21.5.2016, p. 107).

Decisión (UE) 2019/1311 del Banco Central Europeo, de 22 de julio de 2019, sobre la tercera serie de operaciones de financiación a plazo más largo con objetivo específico (DO L 204, 2.8.2019, pp. 100-122)

61 Decisión (UE) 2016/948 del Banco Central Europeo, de 1 de junio de 2016, sobre la ejecución del programa de compras de bonos corporativos (DO L 157, 15.6.2016, pp. 28-32)

62 Decisión (UE) 2015/774 del Banco Central Europeo, de 4 de marzo de 2015, sobre un programa de compras de valores públicos en mercados secundarios (DO L 121, 14.5.2015, pp. 20-24). Fue modificada varias veces. Actualmente se rige por la Decisión (UE) 2020/188 del Banco Central Europeo de 3 de febrero de 2020 sobre un programa de compras de valores públicos en mercados secundarios (DO L 39, 12.2.2020, pp. 12-18). Inicialmente era deuda pública estatal, aunque luego se amplió a deuda de entidades regionales y locales. Véase la introducción a la conferencia de prensa de Mario Draghi (presidente del BCE) y Vitor Constâncio (vicepresidente del BCE). Frankfurt am Main, 3 de diciembre de 2015. Disponible en: https://bit.ly/3ceqqJp.

Decisión (UE) 2014/828 del Banco Central Europeo, de 15 de octubre de 2014, sobre la ejecución del tercer programa de adquisiciones de bonos garantizados (DO L 335, 22.11.2014, pp. 22-24). Actualmente Decisión (UE) 2020/187 del Banco Central Europeo de 3 de febrero de 2020 sobre la ejecución del tercer programa de adquisiciones de bonos garantizados - refundición (DO L 39, 12.2.2020, pp. 6-11). Decisión UE 2014/828 del Banco Central Europeo, de 15 de octubre de 2014, sobre la ejecución del tercer programa de adquisiciones de bonos garantizados (DO L 335, 22.11.2014, pp. 22-24). Actualmente Decisión (UE) 2020/187 del Banco Central Europeo de 3 de febrero de 2020 sobre la ejecución del tercer programa de adquisiciones de bonos garantizados - refundición (DO L 39, 12.2.2020, pp. 6-11).

65 Decisión (UE) 2020/440 del Banco Central Europeo de 24 de marzo de 2020 sobre un programa temporal de compras de emergencia en caso de pandemia (DO L 91, 25.3.2020, pp. 1-4). 
A diferencia del OMT, el PSPP sí que se llegó a implementar ${ }^{66}$. La Decisión (UE) 2015/774 tenía como base jurídica el primer inciso del art. 127(2) TFEU, así como los arts. 3.1, 12.167 y 18.1 de los Estatutos del SEBC. Es decir, se enmarcaba en las obligaciones de conducir la política monetaria y, más específicamente, a través de operaciones de mercados abiertos y crediticios $^{68}$. Las compras eran hechas por los bancos centrales nacionales (BCN), según su participación accionarial en el BCE. Entre las condiciones, además de hacerse solo en mercados secundarios, como ya había sido el caso del OMT, estas no podían superar un tercio de cada emisión de deuda ni un tercio del total de la misma ${ }^{69}$. Los bonos a adquirir debían tener una calidad mínima según las guidelines del BCE sobre admisibilidad de activos de garantía ${ }^{70}$, que eran similares a los que exigen las agencias de calificación para el nivel más bajo de inversión (BCE 2019) ${ }^{71}$. Incluso este nivel mínimo de calidad podía ser obviado por una decisión del Consejo de Gobierno ${ }^{72}$. Para limitar la transferencia del riesgo, y por ende la posible transferencia fiscal (Tuori, 2019: 98), solo en el $20 \%$ los asumía el BCE ${ }^{73}$. El $80 \%$ restante lo asumía cada $\mathrm{BCN}$ sobre la deuda emitida por su propio $\mathrm{Estado}^{74}$. Se garantizaba un valor

66 Para un comentario sobre el PSPP véase Grund y Grle (2016).

67 Este autoriza al Consejo de Gobierno a adoptar decisiones en el marco de la política monetaria que luego permitirán al Consejo Ejecutivo tomar medidas de ejecución, por ejemplo, dando instrucciones a los bancos centrales nacionales (BCN) en un esquema de implementación descentralizada. Apdo. 1 de los considerandos de la Decisión (UE) 2015/774.

69 Art. 3(3) Decisión UE 2015/774.

70 Orientación (UE) 2015/510 del Banco Central Europeo, de 19 de diciembre de 2014, sobre la aplicación del marco de la política monetaria del Eurosistema (DO L 91, 2.4.2015, pp. 3-135; modificada por la Orientación (UE) 2019/1032 del Banco Central Europeo, de 10 de mayo de 2019, por la que se modifica la Orientación (UE) 2015/510 sobre la aplicación del marco de la política monetaria del Eurosistema (DO L 167, 24.6.2019, pp. 64-74)

71 Es decir, un nivel baa (Moody's) o BBB (S\&P y Ficht), que es el que tiene actualmente la deuda pública, por ejemplo, de Colombia, Indonesia, India, Kazajistán, Marruecos, México, Perú, Filipinas o Rusia.

72 Art. 3(2)(c) de la Decisión UE 2015/774.

73 Nota de prensa del Banco Central Europeo de 22 de enero de 2015 «ECB announces expanded asset purchase programme». Disponible en: https://bit.ly/3v5qynb.

74 Preguntas y respuestas del Banco Central Europeo sobre el Public sector purchase programme (PSPP). Ultima actualización 30 de octubre 2020. Disponible en: https://bit. ly/30t0SD8. 
mínimo de compra, autoimponiéndose un tipo máximo de interés ${ }^{75}$ aunque en un contexto de deflación y tipo negativos, en algunos casos el BCE pagaba por adquirirla ${ }^{76}$.

En cuanto a la duración y los efectos, si bien el programa debía finalizar en 2016, luego se prolongó hasta diciembre de 2018, ante la persistencia de las tensiones deflacionarias ${ }^{77}$. La mayoría de los activos aún continuaban en el balance del BCE cuando en 2020 se reiniciaron las compras de deuda pública en el marco del PEPP. Hasta 2020, si comparamos BCE y Reserva Federal, las cifras globales de compras son similares, aunque el BCE se centró más en la compra de deuda pública, como el Banco de Japón y el de Inglaterra, mientras que la Reserva Federal, al menos antes de la COVID-19, en títulos hipote$\operatorname{carios}^{78}$. La diferencia estaría en el impacto que tuvieron los programas en las curvas de tipos de interés de la deuda pública. Mientras que en los demás casos la afectación fue relativamente baja, principalmente porque la deuda comprada era homogénea y de alta calidad, en el caso del programa PSPP (y actualmente del PEPP) tuvo el efecto de sincronizar las curvas, haciendo que estas dependiesen más de la política monetaria que de la economía real (Tuori, 2019: 101).

75 Art. 3(5) de la Decisión UE 2015/774.

76 Nota de Prensa del Banco Central Europeo de 19 de enero de 2017 «ECB provides further details on APP purchases of assets with yields below the deposit facility rate». Disponible en: https://bit.ly/30ppMTQ.

77 Nota de prensa del Banco Central Europeo de 13 de diciembre de 2018 «ECB decides on technical parameters for the reinvestment of its asset purchasing programme». Disponible en: https://bit.ly/3rqo9kR. El propio apdo. 7 del preámbulo de la Decisión (UE) 2015/774/EU establecía que el sistema debía seguir en vigor mientras no se reanudara la inflación.

78 La Reserva Federal, por sus estatutos, podía comprar deuda pública directamente sin acudir a los mercados secundarios y de hecho antes de 2007 ya contaba en sus asientos con más de 700.000 millones de dólares en bonos del tesoro. Con los programas de QE las compras de títulos públicos y privados fue equivalente y estos últimos se centraron en mortgage-backed securities. Con la crisis de la COVID la proporción cambia y en 2020 prácticamente se duplica el balance para comprar bonos federales. Las compras del BCE, a través de los mercados secundarios, se centraron casi siempre en deuda pública, alcanzando los 2400 billones de euros en compras, es decir superando el 20\% del PIB de la Eurozona y, desde la crisis de 2020, ha adquirido deuda pública equivalente al $70 \%$ del total emitido este año. Para la Reserva Federal véase: https:// bit.ly/3emrSMB. Para el BCE ver: https://bit.ly/2PDTNx8. 
En julio de 2017 el BVerfG planteó su segunda cuestión prejudicial ${ }^{79}$ que ante el TJUE, que conocemos como el asunto Weiss, por sus dudas sobre si el APP (aunque en la práctica se centraba en el PSPP) constituía una violación del derecho de la UE. Si bien las dudas del BVerfG recordaban mucho al asunto Gauweiler (Hinarejos, 2019:661), el tono fue totalmente diferente, sin prejuzgar incumplimientos ni amenazar con declarar ultra vires la medida si el TJUE no compartía sus criterios (Mooij, 2019: 452). Además, los objetivos, límites y consecuencias de ambos programas eran diferentes. El OMT no tenía límites de compra y su objetivo era evitar la especulación en el mercado de deuda pública, lo que lo alejaba de los objetivos clásicos de la política monetaria. En cambio, el APP sí que tenía límites (2,5 billones de euros), y su objetivo era evitar la deflación, un objetivo de política monetaria considerado esencial por el BCE. El PEPP quedaba fuera del objeto de litigio.

Las preguntas del BVerfG alTJUE fueron en relación con la naturaleza del PSPP y su compatibilidad con los arts. 123 y 125 TFUE. Respecto al primero, dudaba que por su diseño y escala fuese una medida de política monetaria con efectos tan solo indirectos sobre la política económica ${ }^{80}$. Para ello sopesó los efectos en materia monetaria frente a los económicos, concluyendo que como medidas de política monetaria podían ser desproporcionadas, sin mencionar en ningún momento el test de proporcionalidad strictu sensu; y que en todo caso el BCE no habría facilitado suficientes elementos para poder llegar a una conclusión diferente ${ }^{81}$. Además, ponía en duda que las adquisiciones de deuda pública violasen el art. 123 TFUE (prohibición de financiación monetaria) ya que, aunque realizadas en mercados secundarios, en la práctica, los actores del mercado podrían suponer cierta automaticidad y, por lo tanto, los efectos serían equivalentes a una compra directa ${ }^{82}$. Finalmente, indagaba sobre el reparto de riesgos entre el $\mathrm{BCE}$ y los $\mathrm{BCN}$ en caso de impago, en relación con la non-bailout clause del art. 125 TFUE.

La estructura argumentativa del BVerfG asume que los requisitos que el TJUE menciona en la sentencia Gauweiler (que a su vez cita a Pringle) serían aplicables (de forma vinculante) al caso ${ }^{83}$; que los efectos económicos indirectos de la política monetaria no los transforma ipso facto en medidas

79 Auto del TCFA de 18 de julio de 2017, PSPP, 2 BvR 859/15, 2 BvR 980/16, 2 BvR 2006/15, 2 BvR 1651/15. Disponible en inglés en: https://bit.ly/3kZlo7x. Para un comentario del auto, véase Lang (2018).

80 Auto PSPP, apdos. 119 y sig.

81 Auto PSPP, apdos. 122 y 123.

82 Ibid., apdos. 78 y ss.

83 Ibid., apdo. 79. 
de política económica ${ }^{84}$; y que para valorar la actuación del BCE había que atenerse no solo a las razones esgrimidas en sus decisiones sino también al contexto y el conjunto de reglas que gobiernan la materia ${ }^{85}$, advirtiendo que consideraba que había escasa argumentación por parte del BCE, al menos en cuanto a los efectos de política económica ${ }^{86}$ y a los detalles del blackout period $^{87}$. Finalmente advertía que si el TJUE concluía que el programa PSPP excedía el mandato del BCE o violaba la prohibición de financiación monetaria, estas trasgresiones serían «estructuralmente significativas» y por lo tanto ultra vires según la jurisprudencia del $\mathrm{BVerfG}^{88}$.

La respuesta del TJUE en Weiss ${ }^{89}$ declaró inamisible la quinta cuestión (art. 125 TFUE) por su carácter hipotético ${ }^{90}$ y unió las cuatro restantes en dos grupos, analizando por un lado las relaciones entre la política económica (art. 119 TFUE) y la política monetaria (art. 127(1) TFUE); y por el otro la compatibilidad del PSPP con el art. 123 TFUE.

Como cuestión preliminar el TJUE comienza recordando el gran margen de discrecionalidad del BCE, y recordando a Gauweiler, afirma que no se le exige "que especifique todas las razones de hecho o de Derecho pertinentes»" Considera que las razones vertidas por el $\mathrm{BCE}$ en comunicados de prensa y otros documentos son suficientes para responder al principio de transparencia, incluyendo la valoración de posibles efectos colaterales, todo lo cual hace que la Decisión 2015/774 no sea prima facie inválida ${ }^{92}$. Respecto a la relación entre los art. 119 y 127 TFUE, la sentencia confirma que la separación entre política económica y política monetaria no es absoluta y el hecho de que un programa del BCE tenga efectos (indirectos) sobre la economía no lo privan de su naturaleza monetaria ${ }^{93}$. Si bien el objetivo principal de la política monetaria es el mantenimiento de la estabilidad de precios, su contenido en los Tratados está recogido de modo general y abstracto, pudiendo el BCE precisar cómo

\footnotetext{
Ibid., apdo. 52.

Ibid., apdo. 70.

Ibid., apdo. 123.

7 Ibid., apdo. 93.

88 Ibid., apdo. 66.
}

89 Para comentarios véase: Hinarejos (2019); Mooij (2019); de Boer y van't Klooster (2020).

90 Para un comentario de la respuesta que podría haber dado el TJUE: Mooij (2019: 464).

91 Weiss, apdos. 30-31.

92 Ibid., apdos. 36-37, 38 y 44.

93 Ibid., apdos. 60 y 61. La relación entre objetivos monetarios y económicos del BCE habían creado revuelo en Gauweiler. Hinarejos (2015). 
concretarlo $^{94}$. En relación con el principio de proporcionalidad, considera que el riesgo de deflación era una amenaza real y que las decisiones adoptadas por el BCE para hacerle frente eran apropiadas y, comparado con otras medidas alternativas, no fueron más allá de lo necesario para mitigarlo ${ }^{95}$. La naturaleza temporal del programa y las medidas tomadas para limitar el volumen de compras alejan la posibilidad de que el BCE haya cometido un error manifiesto ${ }^{96}$. Y el hecho de que cada banco central realizara compras por separado reduce los riesgos de transferencia de pérdidas ${ }^{97}$, constituyendo una salvaguarda suficiente contra el riesgo moral.

En relación con el art. 123 TFUE, también recordando a Gauweiler, aplica las condiciones para que una compra en mercado segundario no sea incompatible con dicho artículo ${ }^{98}$. La primera, que la compra no sea equivalente a una adquisición directa, lo que se lograría haciendo no predecibles las compras por el backout period, la indeterminación anticipada del monto de las operaciones y la distribución; sumado a la regla del $33 \%$ impuesta para cada banco ${ }^{99}$, que le impediría vender al programa más de dicho porcentaje de su cartera de bonos de cada Estado. Respecto a la segunda condición, que el programa no desalentase a los Estados para seguir una política presupuestaria equilibrada, el TJUE reconoce que el programa pudiese facilitar las condiciones de financiación de ciertos Estados, aunque su naturaleza temporal y el hecho de que el BCE podía vender en cualquier momento dichos títulos si vislumbrase una relajación en las políticas presupuestarias, así como que las compras cubrían una proporción limitada de la financiación de los Estados ${ }^{100}$, todo ello lo alejaban de ser un incentivo para la relajación.

Así, las sentencias Gauweiler y Weiss constituirían una jurisprudencia coherente que daría gran margen de discrecionalidad al BCE en la determinación de su mandato y, en particular, la delimitación entre medidas monetarias y económicas, reduciendo la capacidad de revisión judicial a supuestos de error manifiesto, lo que cuadraría, en principio, con la limitación autoimpuesta por el BVerfG para ejercer su control ultra vires según la sentencia Honeywell.

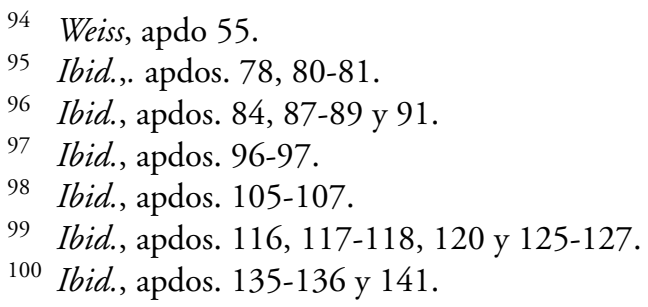




\section{LA POLÍTICA MONETARIA EUROPEA SEGÚN EL BVERFG: DE OMT A PSPP, Y LAS REPERCUSIONES PARA EL PEPP}

A la vista de la interpretación realizada por el TJUE en Weiss, el BVerfG emite su propia sentencia el 5 de mayo de 2020 (sentencia PSPP), considerando que el Gobierno Federal y el Bundestag violaron la Constitución alemana, en particular los arts. 38(1) en conjunción con los art. 20(1) y (2), y 79(3) al no adoptar las medidas necesarias para que el BCE, en sus decisiones de adopción e implementación del PSPP, hubiese evaluado y sustanciado que dichas medidas efectivamente cumplían el principio de proporcionalidad. Prohíbe al Bundesbank seguir participando en el programa si, en el plazo de 3 meses, no se demuestra la proporcionalidad de la medida ${ }^{101}$. Respecto a la sentencia del TJUE reconoce no seguir su interpretación, en particular, porque la evaluación que realizó el Tribunal de Luxemburgo respecto al principio de proporcionalidad no es completa (nachvollziehbar). Al carecer de fundamentos, la interpretación que hace el TJUE sería «incomprensible y, por lo tanto, objetivamente arbitraria» ${ }^{102}$, por lo tanto, ultra vires, y en consecuencia no vinculante para el BVerfG ${ }^{103}$.

La principal crítica contra el BCE (y contra el TJUE) es no haber tenido suficientemente en cuenta los efectos económicos del programa ${ }^{104}$, que no se sopesaron entre ellos para realizar un adecuado control de proporcionalidad ${ }^{105}$, es decir, comparando efectos positivos frente a los negativos ${ }^{106}$; por lo que el control del TJUE sobre la adecuación del programa al mandato del $\mathrm{BCE}^{107}$, que debe ser interpretado de forma restrictiva ${ }^{108}$, habría sido deficiente. Al considerar que el control de proporcionalidad del

101 PSPP, apdo. 235.

102 Ibid., apdo. 118. La traducción es nuestra tomada de la no oficial al inglés ofrecida por el propio TCFA: «simply not comprehensible and thus objectively arbitrary». Hay controversia sobre el significado de la misma, en particular del término «comprehensible» (nachvollziehbaren). Hay quienes suaviza su contenido diciendo que la traducción del alemán al inglés habría alterado su alcance y propone utilizar en su lugar «traceable», poniendo el acento en su poca claridad argumentativa que impediría «trazar» el hilo argumental. Véase Nowag (2020: 4-5).

103 Ibid., apdo. 116.

104 Ibid., apdos. 138-145.

105 Ibid., apdo. 133.

106 Ibid., apdo. 140.

107 Ibid., apdos. 140-142.

108 Ibid., apdo. 144. 
TJUE es incomprensible, desarrolla su propio test ${ }^{109}$. Ante la falta de información por parte del BCE, busca por su cuenta los efectos económicos del programa, todos ellos negativos ${ }^{110}$. Al no haberlos tenido en cuenta el BCE, al menos según la información disponible, el programa estaría fuera de su mandato y, por lo tanto, sería ultra vires ${ }^{111}$.

Por el contrario, acepta la sujeción del programa al art. 123 TFUE mediante las condiciones establecidas en la sentencia Gauweiler, aunque aclara que el control realizado por el TJUE podría haber sido más estricto ${ }^{112}$. En particular critica la falta de información sobre el blackout period (y por lo tanto la garantía de no automaticidad de las compras de deuda) para realizar un adecuado control judicial ${ }^{113}$. Si el BCE mantuviese los bonos hasta su vencimiento, se convertiría en una fuente continua de financiación ${ }^{114}$. Sin embargo, las otras limitaciones (compras según el capital de cada BCN en el BCE, y limitación del $33 \%$ ) serían suficientes para garantizar el cumplimiento del art. 123 TFUE $^{115}$. Concuerda con el TJUE en que la posibilidad de compra a pérdida por los intereses negativos, no sería relevante ${ }^{116}$.

Sobre la quinta pregunta, declarada inadmisible por el TJUE dado su carácter hipotético, es decir la posible redistribución de riesgos en caso de impago , concluye que sería contraria tanto a la Constitución alemana como a los Tratados europeos, por lo que cuenta con que la UE no permitirá que tenga lugar ${ }^{117}$.

Analizaremos a continuación los argumentos de la sentencia en comparación con los del TJUE en la jurisprudencia Gauweiler-Weiss

\section{EL MANDATO, LA INDEPENDENCIA Y LA INTENSIDAD DEL CONTROL}

Según los Tratados el SEBC tiene mandato para desarrollar la política monetaria (art. 127 TFUE) y los Estados miembros la política económica (art. 119 TFUE), con sujeción a un mecanismo de coordinación a nivel de la UE. Sin embargo, en la práctica no se trata de una separación binaria. El

\footnotetext{
109 Ibid., apdo. 164.

110 Ibid., apdos. 169-175.

111 Ibid., apdo. 177.

112 Ibid., apdos. 183-184.

113 Ibid., apdos. 187-191.

114 Ibid., apdo. 195.

115 Ibid., apdo. 217.

116 Ibid., apdo. 218.

117 Ibid., apdos. 222, 227 y 228.
} 
TJUE afirma ${ }^{118}$ que la política monetaria no está definida más que a través de sus objetivos e instrumentos. Y si bien el principal objetivo es la estabilidad de precios, el segundo es apoyar la política económica ${ }^{119}$, con lo que la distinción entre ambas se diluiría. Por lo tanto, el TJUE adopta una definición expansiva de política monetaria (Mooij, 2019: 256), aceptando cualquier medida que afecte a la política monetaria (criterio positivo), sin importar que haya otros efectos (indirectos) sobre la política económica, excluyendo solo aquellas que contravenga prohibiciones claras del Tratado (criterio negativo). Como el BCE cuenta con gran independencia para tomar decisiones técnicas (entre otras, definir los objetivos e instrumentos, y por lo tanto, indirectamente el mandato) el contenido del mandato deviene procedimental: todo lo que el BCE haga es política monetaria, salvo que haya un error manifiesto ${ }^{120}$.

El BVerfG en PSPP no desdice la interpretación del TJUE sobre el alcance de la política monetaria y acepta que pueda haber efectos económicos importantes, incluso incluyendo un listado de posibles efectos económicos (todos ellos negativos) de medidas de política monetaria legítimas ${ }^{121}$. Pero estas, a diferencia del objetivo de estabilidad de precios, no serían parte del núcleo esencial de su mandato y, por ello, no estarían amparadas por la independencia del BCE. Al fin y al cabo, la estabilidad de precios fue impuesta como clave de la política monetaria europea por influencia alemana (Borger 2016). Como una clara reminiscencia monetarista, el BVerfG entiende la independencia del BCE de los poderes públicos, al igual que la del Bundesbank ${ }^{122}$, como una excepción al principio democrático (equivalente a una rule of law; Feichtner, 2020: 1094), justificada solo por el objetivo esencial de la estabilidad de precios $^{123}$.

118 Pringle, apdo. 53; Gauweiler, apdo. 42; Weiss, apdo. 50.

119 Pringle, apdo. 54; Gauweiler, apdo. 43; Weiss, apdo. 51.

120 Gauweiler, apdo. 68, Weiss apdo. 24.

121 PSPP, apdo. 173.

122 Art. 88.2 de la Constitución alemana, art. 130, art. 282(3) TFUE.

123 PSPP, apdo. 103: «The independence enjoyed by the ECB [...] is in conflict with requirements pertaining to the democratic legitimation of political decisions. It had been repeatedly affirmed in the case-law of the Federal Constitutional Court that the transfer of monetary policy competences to an independent European Central Bank [...] are still compatible with democratic principles on the grounds that it takes into account the proven and scientifically supported particularity of monetary policy, which is that an independent central bank is a better guarantor for monetary stability, and thus for the general economic foundation of the budgetary state policy, than organs whose activities are contingent upon monetary supply and monetary value, and which rely on the short-term approval of political actors. The endorsement 
Así, si bien ambos tribunales aceptan que la independencia del BCE no impediría controlar los límites de sus competencias, la intensidad de dicho control sería diferente. Para el BVerfG las medidas destinadas al mantenimiento del control de precios, excepción al principio democrático y, por lo tanto, fuera de su escrutinio ${ }^{124}$, no serían controlables (ni su determinación, inflación del $2 \%$, ni los medios para alcanzarlos) en virtud del principio de independencia. Las demás medidas monetarias, y aquellas que aun teniendo un efecto sobre la estabilidad de precios también tuviesen efectos económicos importantes, deberían someterse a un doble control de proporcionalidad: primero para determinar si son compatibles con el objeto principal del mandato («contained, or were based on» el objetivo de estabilidad de precios) $)^{125}$ y luego para determinar si no van más allá de lo necesario para alcanzar su objetivo ${ }^{126}$. El segundo cuadra con el test de necesidad que normalmente utiliza el TJUE para aplicar el principio de proporcionalidad. Pero el primero, proporcionalidad strictu sensu, rara vez es utilizado por el TJUE y, nunca, como medio para controlar el cumplimiento del principio de atribución de competencias. Una cosa es si se tiene competencia y otra cómo se ejerce (editorial Common Market Law Review, 2020: 969). He aquí un primer malentendido entre las dos sentencias.

\section{PROPORCIONALIDAD STRICTU SENSU COMO NÚCLEO ESENCIAL DEL CONTROL ULTRA VIRES}

El BCE basa sus programas de expansión cuantitativa en la necesidad de luchar contra la deflación y, en definitiva, de responder a su objetivo del mantenimiento de estabilidad de precios, cosa que el TJUE no objeta. El BVerfG duda de que esto sea cierto: "El objetivo de política monetaria del PSPP no es, en principio, discutible (todavía)» ${ }^{127}$; «existen dudas sobre idoneidad del PSPP, en particular, a la luz de la persistencia de los bajos tipos de interés» ${ }^{128}$. Finalmente, acepta la posibilidad: «Sin perjuicio de ello, la conclusión es que

under constitutional law of the ECB's independence hinges on the requirement that its mandate be interpreted restrictively. The ECB mandate is primarily limited to matters of monetary policy serving the aim of stability; it cannot be extended to other areas of policy».

124 Ibid., apdo. 143, citando una extensa jurisprudencia del propio BVerfG.

125 Ibid., apdo. 167.

${ }^{126}$ Ibid., apdo. 168.

127 PSPP, apdo. 165.

128 Ibid., apdo. 166. 
el PSPP es pertinente para alcanzar los objetivos de inflación del $\mathrm{BCE}{ }^{129}$; pero lo somete a un control de proporcionalidad strictu sensu, sopesándolo frente a sus efectos económicos.

Partiendo de la afirmación amplia de que los principios generales se aplican en los contextos de control ultra vires ${ }^{130}$, recuerda su jurisprudencia ultra vires, y en particular el requisito de cambio manifiestos y estructuralmente significativo en la división de competencias. De una forma un tanto confusa, y por ello muy criticada (Martín Rodríguez, 2020: 31), afirma que el principio de proporcionalidad también se aplica a la división de competencias ${ }^{131}$ y lo incluye entre los controles de atribución de competencias, afirmando, para el caso concreto, que la cesión de competencias solo se justificaría si se mostrase la proporcionalidad de los objetivos monetarios y económicos del PSPP sopesados y balanceados uno frente a otro ${ }^{132}$. Es como si el BVerfG hubiese respondido a la incapacidad del TJUE en Weiss ${ }^{133}$ para separar medidas económicas, especialmente las que tuviesen repercusiones fiscales (ultra vires); de las medidas monetarias, en particular, las orientadas a la estabilidad de precios (intra vires), extendiendo esa indefinición al control de proporcionalidad. Este, en vez de limitarlo al momento del ejercicio de la competencia (donde normalmente lo aplican los tribunales, en particular el TJUE) se amplía al del reconocimiento mismo de la competencia (donde lo hace el BVerfG en PSPP). Utilizar el principio de proporcionalidad en este estadio previo actuaría como una compensación que impediría que la indefinición del TJUE sea una carte blanche para el $\mathrm{BCE}^{134}$. Así, solo las medidas proporcionadas cabrían dentro del mandato, y las que no, serían ultra vires.

En cuanto al test de proporcionalidad utilizado, si bien el BVerfG menciona (citando jurisprudencia nacional y europea) adecuación, necesidad y strictu sensu, se centra en el tercero, pidiendo al BCE que valore las repercusiones no monetarias de sus políticas y las compare, para determinar su proporcionalidad. Es el modo que tiene de forzar al BCE a valorar efectos no monetarios de sus políticas. El TJUE en la sentencia Weiss, en cambio, como asumía la competencia de sus acciones, analizaba la proporcionalidad del PSPP solo en cuanto a su adecuación y necesidad de sus objetivos, pero en virtud de su independencia, no exigía al BCE que detallase las posibles

\footnotetext{
129 Ibid.

${ }^{130}$ Ibid., apdo. 113.

131 Ibid., apdo. 119.

132 Ibid., apdo. 165.

133 Weiss, apdos. 60-63.

134 PSPP, apdo. 128.
} 
medidas alternativas, sino que se limitaba a constatar que las había discutido. Es decir, realizó un control formal pero no de fondo.

Si el modo en que el TJUE había realizado el test de necesidad era criticable, ¿por qué el BVerfG se centra en la proporcionalidad strictu sensu? Porque en el primero asumía la validez del mandato y solo criticaba su ejercicio, es decir, jugaba en un terreno que no le era propicio, el de una competencia exclusiva (la política monetaria) donde la institución comunitaria gozaba de una gran independencia. Aunque justificase una violación, esta nunca sería estructuralmente significativa ni excedería el margen de error que el propio BVerfG había asignado al TJUE en su jurisprudencia ultra vires. En cambio, retrotrayendo el control de proporcionalidad al estadio anterior, el del mandato mismo, podía redirigir la discusión al terreno de los principios constitucionales y, en particular, abrir la discusión sobre los límites del mandato mismo del BCE y la legitimidad democrática de aquellas medidas posicionadas en las zonas grises.

El BVerfG nunca mencionó en sus preguntas al TJUE que utilizaría un control de proporcionalidad strictu sensu para determinar el mandato del BCE $y$, aún menos, que este sería el fundamento para argumentar que el PSPP violaba el principio de atribución de competencias y era, por lo tanto, ultra vires. En su sentencia $O M T$, con unos hechos muy similares, no llega siquiera a plantearlo, ateniéndose al esquema clásico de test de adecuación y necesidad ${ }^{135}$. Es más, a diferencia de su jurisprudencia anterior, en $P S P P$ tampoco explica en detalle el cambio de criterio y cómo llega a convertirlo en requisito adicional a los mencionados en la sentencia Honeywell (Bobic y Dawson, 2020: 1971). Desde una perspectiva de observador externo, da la sensación que el BVerfG utiliza la proporcionalidad strictu sensu por razones particulares del caso que no sería generalizables a otros controles ultra vires. De ciertas partes de la sentencia se desprende que el TCFA no solo sospechaba, sino que estaba convencido que el programa no perseguía un objetivo de política monetaria, sino económica. Por ejemplo, cuando afirma que el TJUE olvida los efectos

${ }^{135}$ La sentencia $O M T$ no critica la interpretación que hace el TJUE del principio de proporcionalidad aceptando que el BCE goza de amplia discreción, aunque sometido a ciertas garantías procesales, en particular la obligación de examinar cuidadosa e imparcialmente todos los elementos relevantes del contexto para así dar argumentos razonados a sus decisiones (apdo. 69). Lejos de criticar la aplicación que el TJUE hace del principio de proporcionalidad el BVerfG acepta que la nota de prensa del BCE, junto con los borradores de la reunión, contienen los elementos suficientes para el realizar la revisión (apdo. 71), que el test de adecuación de las medidas no arroja un error manifiesto (apdo. 74), y el test de necesidad tampoco arroja un error manifiesto ya que el BCE sopesó diversas medidas, y descartó algunas por desproporcionadas (apdo. 91). 
reales del PSPP ${ }^{136}$ o cuando achaca al TJUE que, al no distinguir claramente los objetivos de política económica y monetaria (que estarían a diferentes niveles en el mandato del $\mathrm{BCE}$ ), le habría permitido desarrollar su propia agenda económica y, por lo tanto, invadir una competencia en principio de los Estados miembros ${ }^{137}$. Pero al no contar con elementos para demostrarlo, a la luz de la literalidad de las resoluciones del BCE y de la falta de explicación por parte del TJUE de cómo delimitar el mandato que, es verdad, en este punto no es ciertamente analítico; se saca de la chistera un control de proporcionalidad en un estadio previo al que normalmente se utiliza, dejando al TJUE en clara desventaja (Bobic y Dawson, 2020: 1972). Probablemente la idea inicial del BVerfG al plantear las preguntas (recordemos que fue en un tono conciliador) era, en sintonía con Gauweiler, que el TJUE simplemente impusiera requisitos adicionales al BCE para garantizar una cierta separación entre política monetaria y política económica. Esto no fue así, o al menos no lo suficiente a los ojos de BVerfG, por lo que este pretende forzar, con el control de proporcionalidad strictu sensu, una mayor argumentación de la medida sin pretender en ningún momento situarla verdaderamente fuera de la legalidad constitucional alemana. Esto se confirmaría con la exclusión que hace de afectación a la «identidad constitucional» ${ }^{138}$ apartándose, por lo tanto, de accionar el verdadero «botón nuclear», declarando que el programa fuese, per se, ultra vires. Así el TCFA demuestra flexibilidad como para aceptar que, con los necesarios ajustes, pudiese ser compatible con la Constitución alemana.

La tesis de la improvisación se confirmaría por el hecho de que, si realmente se trataba de un malentendido sobre qué, cómo y dónde debía aplicarse el principio de proporcionalidad, en vez de considerar los argumentos de Weiss "simply incomprehensible», el BVerfG siempre podría haber planteado una segunda cuestión prejudicial (Turmo, 2019; Petersen, 2020), como lo ha hecho la Corte constitucional italiana en Taricco ${ }^{139}$. Esto habría sido, además, acorde con su propia jurisprudencia ultra vires de colaboración sincera y evitar el choche salvo que fuese inevitable. Pero creemos que no se trataba de un malentendido, simplemente de un cambio de argumentación.

136 Sentencia PSPP, apdo. 123.

137 Ibid., apdo. 163.

138 Ibid., apdo. 228.

139 Primera cuestión prejudicial: Sentencia de 8 de septiembre de 2015, Taricco I, C-105/14. EU:C:2015:555. Segunda cuestion prejudicial: Sentencia del Tribunal de Justicia de 5 de diciembre de 2017, Taricco II, C-42/17. ECLI:EU:C:2017:936. Para un comentario véase Bonelli (2018) y Piccirilli (2018). 
A pesar de estas críticas que se le puedan hacer al BVerfG, hay algo de verdad en su análisis. Aun aceptando que el BCE, por las circunstancias, se ha visto obligado a adoptar medidas que desde una perspectiva monetaria son "no convencionales», es lógico que el grado de independencia de los bancos centrales también se vea afectado y, por lo tanto, se requiera mayor control (accountability), al menos transparencia, en sus decisiones ${ }^{140}$. Lo que al final reclama el control ultra vires de la sentencia PSPP es argumentar la proporcionalidad de las medidas, y habiéndose superado el plazo impuesto al Bundesbank ( $\mathrm{y}$ a través de este al BCE) para que presente dichos argumentos, y continuando el mismo dentro del programa, es evidente que el BVerfG se ha dado por satisfecho ${ }^{141}$. El propio BCE ha aceptado que su independencia no se ve afectada por un mayor esfuerzo de transparencia (Dawson et. al., 2019), y particularmente en el programa PEPP se ha incrementado el esfuerzo en comunicar las razones de cada medida. Por lo que la sentencia, aunque desproporcionada en la forma, al final habría tenido unos efectos proporcionados en el fondo. El problema principal es que al final los programas del BCE forman parte de un engranaje mayor de gobernanza económica y monetaria, donde se incluyen incluso medidas "paracomunitarias» como el MEDE, que escapan al control judicial del TJUE. Un verdadero control de legitimidad democrática excedería al propio BCE, que no deja de ser un elemento más de la UEM. Es la propia UEM la que necesita mayor legitimidad democrática y ningún tribunal, ni el TJUE ni el BVerfG que, al fin y al cabo, no cuentan con legitimidad directa de los ciudadanos, estarían (valga la redundancia) legitimados para realizar semejante control (de Boer y van't Klooster, 2020).

Sin llegar a tanto, no se puede negar que la política monetaria tiene una afectación importante sobre la economía en general. Puede tener efectos redistributivos en la renta y el ahorro, fomentar o disminuir la creación de empleo, e incluso afectar la lucha contra el cambio climático ${ }^{142}$. Y en el caso europeo, fomentar una convergencia económica difícil de alcanzar a través de otras políticas por la limitada transferencia de competencias, como por ejemplo la política industrial. La independencia con la que gozan los bancos centrales, según postulados monetaristas hoy superados, ha permitido que

${ }^{140}$ Véase el monográfico Maastricht Journal of European and Comparative Law, vol. 26, núm. 1, 2019, en particular Amtenbrink (2019).

${ }^{141}$ Comunicado (enviado por email) por el Bundesbank el 3 de agosto de 2020, citado en Bloomberg «Bundesbank Will Continue Bond Buying as German Court Spat Ends», Disponible en: https://bloom.bg/310yPEr.

142 Discurso de Jean-Claude Trichet, presidente del Banco Central Europeo, ante la Conferencia de Bancos Centrales, Frankfurt, 18 de noviembre de 2010. Disponible en: https://bit.ly/3v8RYc4. 
tales decisiones quedaran fuera del escrutinio parlamentario a diferencia de otras políticas semejantes, como la fiscal. Dejar solo en manos de tecnócratas estas decisiones, más aún cuando otras políticas económicas con mayor escrutinio pierden margen de maniobra y, por lo tanto, aumenta el peso relativo de la política monetaria, podría conllevar graves cuestionamientos de legitimidad (Riles, 2018: 35 y ss.).

Ante este déficit, el BVerfG no aboga por una «renacionalización» de la política monetaria, más que nada porque el mismo problema, seguramente, estaría presente en el Bundesbank. Desde esta lectura, al reclamar más argumentación y transparencia en la toma de decisión de política monetaria en el seno del BCE, y no solo para fundamentar su competencia sino también para valorar los pros y los contras de los efectos de sus decisiones, la sentencia PSPP podría considerarse una contribución en la democratización de la política monetaria (y del euro en particular) como bien público europeo.

\section{LA FINANCIACIÓN MONETARIA COMO VERDADERA LÍNEA ROJA DE LA POLÍTICA MONETARIA}

Desde una perspectiva monetarista clásica, la inflación es consecuencia del exceso de emisión, y este normalmente se produce para financiar unas cuentas públicas desequilibradas. No es de extrañar, por lo tanto, que en el acuerdo Kohl-Mitterand que permitió lanzar la UEM existiese una línea roja dentro del mandato del $\mathrm{BCE}$, en concreto la prohibición absoluta de financiación monetaria (art. 123.1 TFUE).

Tanto el OMT como los PSPP y el actual PEPP incluyen la compra de deuda pública, por lo que es natural que sea un elemento importante de las preguntas que ha hecho (y posiblemente hará) el BVerfG al TJUE. Si bien las compras son en los mercados secundarios, cumpliendo formalmente la letra del Tratado, el BVerfG insistió tanto en Gauweiler como en Weiss en el temor de que los operadores del mercado asumiesen cierta «automaticidad» en las compras lo que, sumado al volumen, podría tener unos efectos similares a los de una financiación monetaria a través de la intermediación de los bancos. En Gauweiler, siguiendo al AG, el TJUE marcó las condiciones para aceptar que los programas de compra no violasen el art. 123 TFUE $^{143}$, aunque en Weiss aclaró que estas podían variar según las características del programa de compra $^{144}$.

143 Gauweiler, apdos. 93-127.

144 Weiss, apdo. 108. 
El BVerfG, en PSPP, analizó una a una esas condiciones con detalle y de modo crítico ${ }^{145}$. En particular, echa en falta más información sobre el blackout period, y que esto le impediría realizar un adecuado control judicial sobre las decisiones del BCE ${ }^{146}$. Sin embargo, a pesar de ello concluye que no hay una "elusión manifiesta del art. 123(1) TFEU»" ${ }^{147}$, dando a entender que a este respecto la sentencia Weiss goza del margen de error que el TJUE tiene derecho en el control ultra vires.

Las salvaguardas esenciales que llevan al BVerfG a semejante conclusión son: la limitación del volumen al $33 \%$ del total de deuda ${ }^{148}$ y la distribución de las compras según el capital de cada $\mathrm{BCN}^{149}$. Juntas garantizarían el carácter no selectivo de las compras, y con ello beneficiar a ciertos Estados ${ }^{150}$. El BVerfG, por lo tanto, traza una línea recta entre la limitación de financiación monetaria y la política de equilibrio presupuestario ${ }^{151}$, y con ello con la política fiscal.

Recuérdese que la política fiscal es para el BVerfG una competencia no transferible y parte de la «identidad constitucional» alemana. Cada acuerdo que afecte o pueda afectar a la misma debe someterse a la votación del Bundestag ${ }^{152}$. Por lo tanto, si hubiese una afectación a la misma, porque hubiese indicios de selectividad en las compras, sería suficiente para declarar el programa ultra vires, probablemente sin posibilidad de matización alguna a través del principio de proporcionalidad. El BVerfG ha levantado el seguro del verdadero botón nuclear, probablemente con un ojo puesto en el PEPP que, recordemos, ya estaba aprobado en el momento de publicarse la sentencia. Y la nota de prensa de la sentencia ${ }^{153}$, insistiendo en que la misma solo afecta el PSPP y no otros programas más recientes, hacen prever que lo peor está por venir.

Según la Decisión 2020/440 del BCE por la que se pone en funcionamiento el PEPP, si bien las compras se distribuirán en función del capital del BCE (art. 5.1), "las compras puede(n) ajustarse [...] para permitir fluctuaciones en la distribución de los flujos de compra a lo largo del tiempo entre

145 PSPP, apdos. 180-215.

146 Ibid., apdo. 189.

147 Ibid., apdo. 216.

148 Ibid., apdo. 202.

149 Ibid., apdo. 203.

${ }^{150}$ Ibid., apdo. 217.

151 Ibid., apdo. 203.

152 Ibid., apdo. 227, en particular toda la jurisprudencia citada.

153 Nota de prensa del TCFA 32/2020 del 5 de mayo 2020 sobre la sentencia PSPP. Disponible en inglés en: https://bit.ly/3ccltkA. 
todas las clases de activos y entre jurisdicciones». Al respecto, en la exposición de motivos se afirma que «es esencial un enfoque flexible de la composición de las compras en el marco del PEPP, a fin de evitar que las perturbaciones actuales de la curva de la deuda soberana agregada de la zona del euro se traduzcan en nuevas distorsiones de la curva de tipos de interés sin riesgo de la zona del euro, garantizando al mismo tiempo que la orientación general del programa abarque todas las jurisdicciones de la zona del euro». Es decir, el programa persigue, abiertamente, objetivos de política económica (atenuar la curva de tipos de interés) y que puede haber, temporalmente, distanciamiento entre el volumen de compras y la distribución del accionariado del BCE, lo que reaviva el fantasma de la transmisión de riesgos. Según datos del $\mathrm{BCE}^{154}$, a finales de enero de 2021 los cuatro países más beneficiados del programa fueron Alemania, Italia, Francia y España con adquisiciones por 188, 136, 133 y 89 mil millones, lo que representan el $24 \%, 17 \%, 17 \%$ y $11 \%$ del total adquirido, cuando según la participación de cada $\mathrm{BCN}$ en el capital del BCE tendría que haber sido del $21 \%, 13 \%, 16 \%$ y $9 \%$ respectivamente. Claramente Italia y España son los dos grandes beneficiarios del programa con compras que superan un $27 \%$ y un $17 \%$ lo que le hubieran correspondido en el PSPP. El volumen y velocidad de compra también es importante. Por ejemplo, las compras del BCE de deuda pública española en 2020 equivalen a toda la deuda emitida ${ }^{155}$. Dicho de otro modo, el BCE transfirió al SEBC el riesgo de impago de un montante equivalente al $25 \%$ de la deuda española emitida en 2020. No está claro cuánto tiempo se mantendrá este desfase, que según la Decisión 2020/440 está llamado a ser temporal. Si hacemos una proyección de datos de la misma información facilitada por el BCE en noviembre de 2020, el nivel de compras de deuda española se estaría desacelerando, reduciendo su peso en el volumen total de compras mucho más rápido que la reducción de las compras de deuda italiana. El programa está llamado a durar mientras dure la «fase de crisis» de la pandemia y su finalización requerirá de una decisión del Consejo de Gobierno ${ }^{156}$.

La otra gran condición del PSPP, la limitación del $33 \%$, directamente no se aplica, por motivos de eficacia, según el art. 4 de la decisión. Las adquisiciones se harán «en la medida en que se considere necesario y proporcionado para hacer frente a las amenazas planteadas por las condiciones económicas y

154 https://bit.ly/3v2N2p3.

155 Entrevista a Luis de Guindos, vicepresidente del BCE, de 11 de enero de 2021 a EuropaPress: «El BCE compró 120.000 millones de deuda española en 2020, el equivalente a la emisión neta del país». Disponible en: https://bit.ly/38lZKVW.

156 Decisión 2020/440, considerando 4. 
de mercado extraordinarias en lo que respecta a la capacidad del Eurosistema para cumplir su mandato». Es discutible que el BCE haya cumplido la carga argumentativa en términos de proporcionalidad que le exigía el BVerfG: menciona en varios apartado la «necesidad» y "proporcionalidad» de las medidas «para contrarrestar los graves riesgos para la estabilidad de los precios, el mecanismo de transmisión de la política monetaria y las perspectivas económicas» ${ }^{157}$ pero no llega a analizar en detalle los efectos económicos indirectos —en clave proporcionalidad strictu sensu — ni medidas alternativas que podrían alcanzar objetivos similares —en clave test de necesidad—, sin embargo, la sentencia PSPP no plantea que la prohibición de financiación monetaria sea modulable por tales principios. Ni por estos ni por otros utilizados en la Decisión 2020/440, como la «excepcionalidad» del contexto de la pandemia o la "temporalidad» (aunque sin fijar una fecha clara) en la duración. El BVerfG entiende la prohibición del art. 123 TFUE como una prohibición tajante, de respuesta binaria. Se pueden fijar condiciones para evitar que haya financiación monetaria, pero una vez que esta se produce, no se puede justificar.

Se plantea la cuestión de si la pérdida de las dos salvaguardas esenciales que identificó el BVerfG en PSPP para evitar la «selectividad», harían que este considere que hay financiación monetaria y por ende, usurpación de la política fiscal y, en consecuencia, actuación ultra vires.

Los otros elementos, como el volumen del programa, no ayudan a adoptar una respuesta negativa. Si el PSPP autorizaba compras por sesenta mil millones de euros, el PEPP (ampliado dos veces en junio y diciembre 2020), alcanza actualmente los 1850 miles de millones ${ }^{158}$, es decir casi un $20 \%$ de la deuda pública de la Eurozona a finales de $2019^{159}$, multiplicando exponencialmente los efectos de la relajación en el control de gasto. El 17 de junio 2020 el partido de ultraderecha AfD presentó un recurso contra el PEPP ante el $\mathrm{BVerfG}^{160}$, por lo que estamos a las vísperas de un nuevo capítulo del diálogo TJUE-BVerfG en materia de política monetaria.

157 Ibid.

158 Información del BCE sobre el Pandemic emergency purchase programme. Actualizado a 22 de enero de 2021. Disponible en: https://bit.ly/3qtchxi.

159 Estadistica de Eurostat «General government gross debt - quarterly data». Actualizado a 22 de octubre 2020. Disponible en: https://bit.ly/3ccmoS4.

160 Nota de prensa del Official Monetary and Financial Institutions Forum de 17 de junio de 2020 «Fresh German legal battle over ECB easing». Disponible en: https:// bit.ly/3eoJLdU. 


\section{PRIMACÍA Y EFECTIVIDAD DE LAS DECISIONES JUDICIALES EN MATERIA DE UEM}

La respuesta inicial de las instituciones europeas a la sentencia PSPP no se hizo esperar. El mismo 5 de mayo el BCE tomó nota de la sentencia y refirmó su compromiso con la consecución de una política monetaria que permitiese elevar la inflación y mantenerla a los niveles fijados para el mediolargo plazo, y recordó la sentencia Weiss del TJUE ${ }^{161}$. El 8 de mayo el TJUE emitió un comunicado de prensa en donde confirmaba que no comentaría decisiones nacionales y recordó que las cuestiones prejudiciales son vinculantes, su monopolio para declarar la ilegalidad de actos de instituciones de la Unión, y la obligación de los jueces nacionales de aplicar el derecho de la Unión de forma total como único modo de garantizar la igualdad entre Estados miembros ${ }^{162}$. Por su parte, la presidenta de la Comisión Europea, en su comunicado de prensa de 8 de mayo reafirmó el carácter exclusivo de la competencia de la Unión en materia de política monetaria, el principio de primacía del derecho de la Unión sobre el derecho nacional y la obligatoriedad de las decisiones del TJUE para los jueces nacionales ${ }^{163}$. Finalmente, el presidente del Bundesbank aceptó la sentencia y comenzó a trabajar en la respuesta que daría el $\mathrm{BCE}$ en el plazo fijado por la sentencia, reafirmando que seguiría trabajando por la independencia del $\mathrm{BCE}^{164}$.

El problema del choque entre el principio de primacía, y la jurisprudencia ultra vires del BVerfG, siempre estuvo latente (Grimm, 2020). Hasta la sentencia PSPP, el BVerfG había actuado como un «dog that barks but does not bite» (Weiler, 2009; Schmid, 2001). Por ello algunos interpretaron que la sentencia PSPP había hecho sonar «las trompetas a las puertas de Jericó» (Martín Rodríguez, 2020). Se habría roto el diálogo TJUE/BVerfG en el marco del «constitutional pluralism» (Walker, 2002: 2016) por el quebrantamiento del principio de primacía (siempre entendido desde un punto de vista

161 Nota de prensa del Banco Central Europeo de 5 de mayo de 2020 «ECB takes note of German Federal Constitutional Court ruling and remains fully committed to its mandate». Disponible en: https://bit.ly/38qgxr1.

162 Nota de prensa Nro. 58/20 del Tribunal de Justicia de 8 de mayo de 2020 «Press release following the judgment of the German Constitutional Court of 5 May2020». Disponible en: https://bit.ly/3t1PZEh.

163 Comunicado de la Comisión Europea del 10 de mayo de 2020 «Statement by President VON DER LEYEN». Disponible en: https://bit.ly/38nRSmR.

164 Comunicado del Bundesbank del 5 de mayo de 2020 «Statement by Bundesbank President Jens Weidmann on the judgement of the Federal Constitutional Court (Bundesverfassungsgericht)». Disponible en: https://bit.ly/3t0AU64. 
jerárquico) y, por lo tanto, era hora de iniciar un proceso de incumplimiento contra Alemania (Nguyen y Chamon, 2020). No compartimos esta visión.

Sin entrar en detalles en el desarrollo jurisprudencial reciente, su debilitamiento ante normas sin efecto directo, o la distinción entre efecto de exclusión y efecto de sustitución (López Escudero, 2019; Dougan, 2019; Tuominen, 2020), la nota de prensa del TJUE del 5 de mayo 2020 constituye una síntesis esquemática de la doctrina del TJUE. La primacía del derecho de la Unión y, en particular, el carácter vinculante de la interpretación que hace el TJUE sobre el mismo, así como el monopolio que tiene para anularlo, son el único modo que hay para asegurar la equidad entre los Estados miembros. Es decir, no hay una fundamentación en términos de legitimidad democrática, como la que utiliza el BVerfG para fundamentar su derecho al control ultra vires, sino que más bien se trata de una necesidad práctica para que el derecho de la Unión funcione adecuadamente ${ }^{165}$. La primacía es una protección del principio de igualdad de los Estados, y en definitiva de su identidad, de acuerdo con el art. 4.2 TFUE, al garantizar la aplicación uniforme del derecho de la UE en todos y cada uno de los miembros. Pero la jurisprudencia del TJUE acepta limitaciones a la primacía, en lo que nos interesa, para casos de colisión con derechos fundamentales protegidos por las constituciones y el derecho de la Unión, por lo que no se trataría de un principio absoluto ${ }^{166}$.

Aunque parezca lo contrario, la visión del BVerfG es, al menos, compatible con este razonamiento. El BVerfG no desconoce la legitimidad del TJUE. Es más, intenta fundamentarse en todo lo posible en su jurisprudencia, y sus discrepancias siempre van precedidas de reafirmaciones sobre sus responsabilidades con el proceso de integración europea (Integrationsverantwortung) ${ }^{167}$. Este distingue la agenda europea (Integrationsprogramm) del marco institucional, y siente la obligación (junto con el Bundestag) de mantener al segundo dentro de los límites del primero ${ }^{168}$. Es decir, plantea su control como una contribución al proceso de integración europea y, en particular, para que sus instituciones se mantengan dentro de los límites de actuación que le corresponden. No hay una crítica a la legitimidad de la institución per se, sino a los efectos de alguna(s) de sus actuaciones.

165 Para un comentario sobre el efecto útil y la primacía específicamente en la UEM véase Fabbrini (2015).

166 Sentencia de 19 de diciembre de 2019, Deutsche Umwelthilfe, C-752/18, EU:C: 2019:1114. Sentencia de 17 de enero de 2019, Dzivev y otros, C-310/16, EU:C:2019:30.

167 PSPP, apdo. 108.

168 Ibid., apdo. 109. 
Si aceptamos que tanto el TJUE fundamenta su primacía, y el BVerfG su control ultra vires, en el terreno del effet utile; solo habría un verdadero choque (y por lo tanto un incumplimiento del derecho de la Unión) si la sentencia PSPP, además de declarar el carácter ultra vires del programa PSPP y de la sentencia Weiss, le hubieran quitado efectos prácticos. Esto, como ya dijimos, no ha ocurrido ya que el BVerfG ha aceptado los argumentos del Bundesbank para justificar la proporcionalidad de la medida. Es decir, la decisión PSPP sería una declaración ultra vires "en suspenso», que nunca se ha materializado. Pero la sentencia del BVerfG no por ello deja de ser un ejemplo de desobediencia a una sentencia prejudicial del TJUE, muy criticable a la luz del derecho de la Unión, con un tono totalmente desproporcionado que puede generar un daño reputacional al TJUE (Martín Rodríguez, 2020) y un efecto de emulación para otros tribunales constitucionales que ya se han reservado (o pretendan asumir ahora) el control ultra vires $^{169}$.

A pesar de esto, quedan algunas cuestiones relacionadas con la primacía por resolver que pueden resultar inquietantes en caso de que tengamos un nuevo enfrentamiento, esta vez en torno al PEPP. En primer lugar, nos preguntamos si el BVerfG no debió haber planteado una segunda cuestión prejudicial, particularmente ante la falta de comprensión del razonamiento del TJUE en Weiss. En M.A.S. y M.B. ${ }^{170}$, que era la segunda cuestión prejudicial plantada en el caso Taricco, el TJUE llegó a flexibilizar la primacía al denotar que su aplicación estricta suponía una violación a un derecho fundamental protegido constitucionalmente (Rauchegger, 2018), lo que demuestra la conveniencia de reutilizar el instrumento a modo de «revisión» en el marco del diálogo entre jueces (Dubout, 2018; Sarmiento, 2018). Esto, además, sería compatible con el principio de cooperación leal que se exige a los Estados (art. 4.3 TUE). Además, las recomendaciones a los órganos jurisdiccionales nacionales, relativas al planteamiento de cuestiones prejudiciales ${ }^{171}$ específicamente indican que la «Secretaría del Tribunal de Justicia se mantiene en contacto con el órgano jurisdiccional remitente, al que envía copia de todos los escritos procesales y, en su caso, las solicitudes de precisiones o de aclaraciones que se estimen ineludibles para responder útilmente a las cuestiones planteadas por

169 Recordemos que el Tribunal Constitucional checo, en la sentencia de 31 de enero de 2012, ya declaró ultra vires la sentencia Landtová, EU:C2011:415. Y el Tribunal Supremo danés en su sentencia de 6 de diciembre de 2016 rechazó aplicar la decisión Dansk Industri (EU:C:2016:278) por considerar que violaba el reparto de competencias fijada en la ley danesa de adhesión.

170 Sentencia de 5 de diciembre de 2017, M.A.S. y M. B., C-42/17, EU:C:2017:936.

171 Recomendaciones a los órganos jurisdiccionales nacionales, relativas al planteamiento de cuestiones prejudiciales. DO C 380, 8.11.2019, pp. 1-9. Ver esp. punto 30 
dicho órgano». No consta en la sentencia PSPP si el BVerfG requirió precisiones o aclaraciones al TJUE para mantener una "cooperación sincera»" ${ }^{172}$.

La segunda pregunta que se nos plantea es si, en el hipotético caso que el BVerfG efectivamente prohibiese un acto de la Unión, con efectos, ¿podría la Comisión iniciar un proceso por incumplimiento fundándose en el principio de primacía? Hay pocos antecedentes de condena por actuación de jueces nacionales (EU:C:2009:695 y EU:C:2018:811) y la Comisión ha sido renuente a iniciar procedimientos por incumplimiento basándose exclusivamente en decisiones judiciales (Taborowski, 2012) ${ }^{173}$. Es más, también dudamos que se pueden iniciar un procedimiento de responsabilidad. Aunque teóricamente posible según la jurisprudencia Köbler, solo se registran un puñado de casos en donde se haya declarado la responsabilidad del Estado por decisiones judiciales (Varga, 2020: 9-12), lo que demuestra lo difícil que es compatibilizar la efectividad del derecho comunitario frente a la independencia judicial que este también protege. Si es difícil declarar la responsabilidad, más aún será declarar el incumplimiento, donde normalmente hay un margen de error mayor.

Forzar la aplicación de la primacía no parece, por lo tanto, una tarea fácil. Además, alimentaría la narrativa épica de que se trata de un enfrentamiento vertical entre la UE y un Estado miembro cuando la realidad es más compleja. Las instituciones del estado alemán, en particular la Cancillería y el Bundestag, hasta ahora han participado activamente en las decisiones tomadas en materia de UEM y las han refrendado. Y los esfuerzos recientes, tanto del BCE como del Bundesbank, por explicar sus decisiones ante el Bundestag (en particular sobre el PEPP) parecen haber dado sus frutos y este no ve, $a$ priori, una grave usurpación de sus competencias ${ }^{174}$. Sin mencionar las contradicciones entre la proeuropea Sala Primera y antieuropea Sala Segunda del TCFA (Mayer, 2020: 1116; Wendel, 2020). Solo una facción minoritaria, específicamente $\mathrm{AfD}$, parece ver un problema de legitimación democrática y estar dispuesta a dar batalla ante el BVerfG. La pregunta que nos cabe si el BVerfG, a través de una interpretación muy particular del derecho a voto

172 Honeywell, apdo. 100.

173 Si habría casos indirectos, por ejemplo, procedimientos de incumplimiento por falta de transposición del derecho de la Unión en supuestos en donde la norma nacional que la transponía fue anulada por la justicia nacional. Ver por ejemplo nota de prensa de la Comisión Europea de 31 de mayo de 2012 «Data retention: Commission takes Germany to Court requesting that fines be imposed». Disponible en: https://bit.ly/3kYpEUZ.

${ }^{174}$ Comparecencia a puertas cerradas de Jens Weidmann, presidente del Bundesbank, ante el Bundestag, 16 de septiembre de 2020. Recogida en Reuters «Bundesbank chief defends ECB bond purchases in wake of court case». Disponible en: https://reut. $\mathrm{rs} / 3 \mathrm{eo} 02 \mathrm{j} 5$. 
del art. 38 de la Constitución alemana está sirviendo de altavoz para que opiniones minoritarias, incluso de particulares ${ }^{175}$, y por lo tanto de escasa legitimación democrática, sean asumidas como la de toda Alemania. La UE no debería contribuir a esto a través de un recurso de incumplimiento en base al principio de primacía del derecho de la Unión.

\section{CONCLUSIONES}

Al principio de este artículo nos planteábamos la pregunta de si la jurisprudencia reciente del BVerfG, y en particular la sentencia PSPP, además del conflicto que evidentemente ha abierto con el TJUE, podría ser entendida como una contribución al debate sobre la democratización de la política monetaria. A lo largo de estas páginas hemos intentado analizar el cómo y el porqué de los desencuentros entre ambos tribunales y creemos que, tomando un poco de perspectiva, la respuesta debe ser afirmativa.

La política monetaria, tal como era cuando se diseñó la UEM, no es aplicable a los desafíos a que se enfrentan hoy en día los bancos centrales. Ni la inflación es un problema acuciante, ni las herramientas clásicas (subida de tipos de interés) son útiles. Es evidente que los sucesivos programas que ha desarrollado el BCE no persiguen un objetivo de estabilidad de precios, sino más bien el de reactivación económica y, en todo caso, el de estabilización de los mercados (primero financieros y luego de deuda pública). Tanto el TJUE (a través de su indefinición sobre efectos económicos indirectos) como el BVerfG (a través del siempre maleable principio de proporcionalidad) han aceptado esta ampliación, de facto, del mandato del BCE. El mandato del BCE y, por lo tanto, el control ultra vires sobre el mismo, se ha convertido en una cuestión de argumentación y transparencia, requisitos en definitiva procedimentales más que de fondo. Esta realidad se enfrenta, sin embargo, a dos problemas sin resolver.

El primero es cómo encaja esta realidad con la narrativa del BVerfG sobre el control ultra vires que, recordemos, se fundamenta en la legitimidad democrática en la toma de decisiones. A nuestro entender, el TJUE erró al escudar su argumento en la independencia del BCE, más cuando el «whatever it takes» era un reemplazo a decisiones políticas de envergadura en materia fiscal que no se tomaban por un bloqueo en las posiciones. El BCE hizo lo que los gobiernos ( $\mathrm{y}$ en particular el alemán) consideraba que no era

175 Recuérdese que en Gauweiler ya se plantearon dudas sobre si el procedimiento mismo violaba el art. 263 TFEU. Véase a este respecto Perinice (2014: 4). 
políticamente posible hacer. Muestra de esto es que el primer programa (OMT) mantenía el requisito de condicionalidad, dando a entender que era una medida accesoria al MEDE, que había pasado por un complejo mecanismo de ratificación por autoridades con la máxima legitimación democrática. No fue así en el PSPP, aunque las garantías de no transferencia de riesgos fueron suficientes como para que no se accionase el «botón nuclear» de considerarlo financiación monetaria (que por su volumen lo era, pero sin solidaridad de riesgos de impago). El PEPP ya no tiene este elemento y la realidad indica que está beneficiando a unos Estados más que a otros. Con lo cual, no solo se puede cuestionar que vaya más allá del mandato del BCE (en teoría justificable con una argumentación adecuada de proporcionalidad), y que haya financiación monetaria (en teoría justificable por la compra en mercados secundarios), sino que ya nos enfrentamos al verdadero problema, la afectación al elemento de «identidad constitucional», la cuestión de la solidaridad fiscal. Desde la perspectiva alemana se está intentando atajarlo a través de una compleja diplomacia monetaria que incluye la rendición de cuentas del Bundesbank (y a través de él, del BCE) ante el Bundestag. No hay votaciones formales, como exigió el BVerfG para aprobar los rescates, pero hay una accountability. Paralelamente, dicho control legislativo también lo estaría haciendo el Parlamento Europeo, con vistas con la presidenta del $\mathrm{BCE}$, aunque probablemente con menos rigor.

El BVerfG habría acertado en subrayar los problemas de legitimidad democrática de la política monetaria, entendida como lo hacemos hoy, con herramientas de gran repercusión en la economía real. Es verdad que probablemente lo hacía pensando en «el» problema alemán (la solidaridad fiscal) aunque la misma lógica se aplica a otras cuestiones no siempre analizadas, como los efectos en el consumo desmedido y sus repercusiones en el cambio climático, por ejemplo. Si bien el BCE ha avanzado mucho en transparencia, probablemente se necesita hacerlo aún más y, en particular, promover el estudio de los efectos no deseado de sus políticas, y al menos debatir estos resultados con los actores afectados. Por estas razones, creemos que la discusión judicial no ha sido en vano.

El segundo problema, también relacionado con la legitimidad, tiene más difícil solución. El control ultra vires del BVerfG, basado en la legitimidad democrática, y el principio de primacía, basado en el principio de efectividad (e igualdad de los Estados) es en el estado actual, irresoluble. La imposición de la primacía por parte del TJUE es inviable, más cuando la desobediencia viene de un tribunal constitucional. El BVerfG ha ido subiendo el tono y llegado hasta el mismo límite de la desobediencia, con una declaración ultra vires «en suspenso». La paradoja es que la legitimidad democrática, más entendida como un derecho individual como lo hace el 
BVerfG, no es absoluta. Si esta sirve de fundamento para que un partido de extrema derecha tenga un altavoz de su discurso, cuando el resto de instituciones, con alta legitimidad, aceptan la no afectación de los intereses de sus representados, participan en la toma de decisiones a través de las instituciones de la UE y las ejecutan, no forzadamente, nos encontraríamos ante un control formal pero no sustancial de legitimidad. Tampoco nos parece legítimo, declarar una sentencia del TJUE ultra vires fundándose en la incomprensión de sus argumentos, cuando se disponía de la posibilidad de pedir aclaraciones a través de una segunda cuestión prejudicial ¿No se podría decir, en este caso, que el BVerfG ha tomado una decisión ultra vires?

Para finalizar con positividad, y en vistas a un nuevo conflicto en relación al PEPP, nos preguntamos si el contexto que estamos viviendo, y en particular el nuevo Marco Financiero Plurianual 2021-2027 (Sánchez-Barrueco, 2021) acordado en el Consejo Europeo de 17-21 de julio 2020, incluyendo la creación de nuevos recursos propios; y temporalmente para hacer frente a la pandemia de la COVID-19 y a petición de los jefes de Estado o de Gobierno, un Instrumento Europeo de Recuperación («Next Generation EU») alimentado en un $50 \%$ por empréstitos obtenidos por la Comisión Europea en los mercados financieros internacionales («coronabonos»; Martucci, 2020), puesto en funcionamiento por el Reglamento del Consejo 2020/2094 (Olesti Rayo, 2021)aunque recientemente (26 de marzo 2021) suspendida su ratificación en Alemania por el BVerfG; todo ello no constituye, de facto, ese momentum constitucional que reclamaba en Lisboa el BVerfG para aceptar más transferencias. Tal vez si una guerra hizo posible la cesión de soberanía en materia del carbón y del acero, una pandemia lo hará en materia fiscal.

\section{Bibliografía}

Adamski, D. (2015). Economic constitution of the euro area after the Gauweiler preliminary ruling. Common Market Law Review, 52 (6), 1451-1490.

Amtenbrink, F. (2018). Economic and Monetary Union. En P. J. Kuijper, F. Amtenbrink, D. Curtin, B. De Witte, A. McDonnell, S. van den Bogaert (eds.). The Law of the European Union (pp. 883-950). Alphen Aan den Rijn: Kluwer Law International.

Amtenbrink, F. (2019). The European Central Bank's intricate independence versus accountability conundrum in the post-crisis governance framework. Maastricht Journal of European and Comparative Law, 26 (1), 165-179. Disponible en: https://doi.org/10.1177/1023263X18822789.

Andrade, P., Breckenfelder, J., De Fiore, F., Karadi, P. y Tristani. O. (2016). The ECB's asset purchase programme: an early assessment. Working Paper Series: Discussion Papers; 1956. Disponible en: https://bit.ly/2O4BKjf. 
Azpitarte Sánchez, M. (2016). Integración europea y legitimidad de la jurisdicción constitucional. Revista de Derecho Comunitario Europeo, 55, 941-975. Disponible en: https://doi.org/10.18042/cepc/rdce.55.05.

BCE (2002). The accountability of the ECB. Monthly Bulletin, noviembre, 45-57.

BCE (2019). Eurosystem Credit Assessment Framework (ECAF). European Central Bank. Disponible en: https://bit.ly/3uQStXT.

Bobes Sánchez, M. J. (2010). La integración europea según el Tribunal Constitucional Federal Alemán. Comentario a la Sentencia del BVerfG sobre el Tratado de Lisboa. Revista Española de Derecho Europeo, 33, 157-186.

Bobic, A. y Dawson, M. (2020). National courts Making sense of the «incomprehensible»: The PSPP Judgment of the German Federal Constitutional Court. Common Market Law Review, 57 (6), 1953-1998.

Bonelli, M. (2018). The Taricco saga and the consolidation of judicial dialogue in the European Union: CJEU, C-105/14 Ivo Taricco and others, ECLI: EU: C: 2015: 555; and C-42/17 MAS., MB, ECLI: EU: C: 2017: 936 Italian Constitutional Court, Order no. 24/2017. Maastricht Journal of European and Comparative Law, 25 (3), 357-373. Disponible en: https://doi.org/10.1177/1023263X18773046.

Borger, V. (2016). Outright Monetary Transactions and the stability mandate of the ECB: Gauweiler. Common Market Law Review, 53 (1), 139-196.

Bursi, M. (2020). La sentenza del Bverfg sul public sector purchase programme. Un’Europa sempre più difficile. Consulta Online, 2, 385-405.

Capeta, T. (2018). The role of Courts in economic governance in the European Union. En F. J. Carrera Hernández (dir.). Hacia una nueva gobernanza económica de la Unión Europea? (pp. 155 -190). Cizur Menor: Aranzadi.

Castillo de la Torre, F. (2009). La sentencia del Tribunal Constitucional Federal Alemán de 30.06.2009, relativa a la aprobación del Tratado de Lisboa-Análisis y Comentarios. Revista de Derecho Comunitario Europeo, 34, 969-1010.

Corti Varela, J., Porras Belarra, J. y Román Vaca, C. (2011). El control ultra vires del Tribunal Constitucional alemán. Comentario de la Decisión de 06.07.2010 (2 bvr 2661/06, Honeywell). Revista de Derecho Comunitario Europeo, 15 (40), 827-852.

Craig, P. (2011). Competence and member state autonomy: Causality, Consequence and Legitimacy. En H. W. Micklitz y B. de Witte (eds.). The European Court of Justice and the Autonomy of the Member States (pp. 11-34). Cambridge: Intersetia.

Craig, P. y Markakis, M. (2016). Gauweiler and the Legality of Outright Monetary Transactions. European Law Review, 41 (1), 4-24.

Curtin, D. (2017). «Accountable Independence» of the European Central Bank: Seeing the Logics of Transparency. European Law Journal, 23 (1-2), 28-44. Disponible en: https://doi.org/10.1111/eulj.12211.

Dawson, M., Maricut-Akbik, A. y Bobić, A. (2019). Reconciling Independence and accountability at the European Central Bank: The false promise of Proceduralism. European Law Journal, 25 (1), 75-93. Disponible en: https://doi. org/10.1111/eulj.12305. 
de Boer, N. y van't Klooster, J. (2020). The ECB, the courts and the issue of democratic legitimacy after Weiss. Common Market Law Review, 57 (6), 1689-1724

Dougan, M. (2019). Primacy and the Remedy of Disapplication. Common Market Law Review, 56 (6), 1459-1508.

Dubout, E. (2018) La primauté du droit de l'Union et le passage au pluralisme constitutionnel. Revue Trimestrielle de Droit Européen, 54 (3), 563-586.

Editorial Common Market Law Review (2020). Not mastering the Treaties:The German Federal Constitutional Court's PSPP judgment. Common Market Law Review, 57 (4), 965-978.

Eich, S. y Tooze, A. (2016). The Great Inflation. En A. Doering-Manteuffel, L. Raphael y T. Schlemmer (eds.). Vorgeschichte der Gegenwart. Dimensionen des Strukturbruchs nach dem Boom (pp. 173-196). Göttingen: Vandenhoeck and Ruprecht. Disponible en: https://doi.org/10.13109/9783666300783.173.

Fabbrini, F. (2015). After the OMT case: The Supremacy of EU Law as the Guarantee of the Equality of the Member States. German Law Journal, 16 (4), 1003-1023. Disponible en: https://doi.org/10.1017/S2071832200019970.

Feichtner, I. (2020). The German Constitutional Court's PSPP Judgment: Impediment and Impetus for the Democratization of Europe. German Law Journal, 21 (5), 1090-1103. Disponible en: https://doi.org/10.1017/glj.2020.60.

Friedman, M. (1968). The Role of Monetary Policy. American Economic Review, 58 (1), $1-17$.

Fromage, D., Dermine, P., Nicolaides, P. y Tuor K. (2019). ECB independence and accountability today: Towards a (necessary) redefinition? Maastricht Journal of European and Comparative Law, 26 (1), 3-16. Disponible en: https://doi. org/10.1177/1023263X19827819.

Galetta, D. y Ziller, J. (2020). ¿Kkarlsruhe über alles? La insoportable pesadez del juez constitucional alemán (sobre la sentencia del "Zweiter Senat" del Tribunal Constitucional Federal alemán del 5 de mayo de 2020 relativa al programa PSPP del Banco Central Europeo). Revista Española De Derecho Europeo, 73-74, 179-212. Disponible en: https://doi.org/10.37417/REDE/num7374_2020_390.

Garben, S. (2019). Competence Creep Revisited. Journal of Common Market Studies, 57 (2), 205-222. Disponible en: https://doi.org/10.1111/jcms.12643.

González Pascual, M. (2010). El Tribunal Constitucional alemán en la construcción del espacio europeo de los derechos. Cizur Menor: Civitas-Thomson Reuters.

Goodhart, C. y Jensen, M. (2015). Currency School versus Banking School: an ongoing confrontation. Economic Thought, 4 (2), 20-31.

Grimm, D. (2020). A Long Time Coming. German Law Journal, 21 (5), 944-949. Disponible en: https://doi.org/10.1017/glj.2020.55.

Grund, S. y Grle, F. (2016). The European Central Bank's public sector purchase programme (PSPP), the prohibition of monetary financing and sovereign debt restructuring scenarios. European Law Review, 41 (6), 781-803.

Herdegen, M. (1998). Price Stability and Budgetary Restraints in the Economic and Monetary Union: the Law as Guardian of Economic Wisdom. 
Common Market Law Review, 35 (1), 9-32. Disponible en: https://doi. org/10.1023/A:1018345518563.

Hinarejos, A. (2015). Gauweiler and the Outright Monetary Transactions Programme: The Mandate of the European Central Bank and the Changing Nature of Economic and Monetary Union: European Court of Justice, Judgment of 16 June 2015, Case C-62/14 Gauweiler and others v Deutscher Bundestag. European Constitutional Law Review, 11 (3), 563-576. Disponible en: https://doi. org/10.1017/S1574019615000346.

Hinarejos, A. (2019). El diálogo judicial en curso y los poderes del BCE: la sentencia Weiss. Revista de Derecho Comunitario Europeo, 63 (2), 651-668. Disponible en: https://doi.org/10.18042/cepc/rdce.63.09.

Issing, O. (1999). The Eurosystem: Transparent and Accountable or 'Willem in Euroland'. Journal of Common Market Studies, 37 (3), 503-519. Disponible en: https://doi.org/10.1111/1468-5965.00175.

Lang, A. (2018). National Courts Ultra vires review of the ECB's policy of quantitative easing: an analysis of the German Constitutional Court's preliminary reference order in the PSPP case. Common Market Law Review, 55 (3), 923-951.

Lastra, R. M. (1992). The Independence of the European System of Central Banks, Harvard International Law Journal, 33 (2), 475-520.

López Castillo, A. (2011). La tentativa de respuesta europea a la crisis del Euro y de la Deuda (griega) al amparo del Tribunal Constitucional Federal Alemán. Comentario sucinto de la sentencia de 07.09. 2011 (2 bvr 987/10, 1485/10, 1099/10). Revista de Derecho Comunitario Europeo, 15 (39), 487-502.

López Escudero, M. (2019). Primacía del derecho de la Unión Europea y sus límites en la jurisprudencia reciente del TJUE. Revista de Derecho Comunitario Europeo, 64 (3), 787-825. Disponible en: https://doi.org/10.18042/cepc/rdce.64.01.

Magnette, P. (2000). Towards 'Accountable Independence'? Parliamentary Controls of the European Central Bank and the Rise of a New Democratic Model. European Law Journal, 6 (4), 326-340. Disponible en: https://doi.org/10.1111/14680386.00111.

Martín Rodríguez, P. (2020). Y sonaron las trompetas a las puertas de Jericó... en forma de sentencia del Bundesverfassungsgericht. Revista General de Derecho Europeo, 52, 4.

Martín y Pérez de Nanclares, J. (2011). Órdago del Tribunal Constitucional Alemán al Proceso de Integración Europea (algo más que una Sentencia crítica con el Tratado de Lisboa). Revista d'Estudis Autonòmics i Federals, 13, 97-145.

Martucci, F. (2015). La Cour de justice face à la politique monétaire en temps de crise de dettes souveraines: l'arrêt Gauweiler entre droit et marché. Cabiers de Droit Européen, 51 (2), 493-534.

Martucci, F. (2020). "Ce n'est pas de la dette, c'est de l'investissement»: des coronabonds aux obligations du plan de relance. Revue des affaires europeennes, 2, 299-313.

Mayer, F. (2020). To Boldly Go Where No Court Has Gone Before. The German Federal Constitutional Court's ultra vires Decision of May 5, 2020. German 
Law Journal, 21 (5) 1116-1127. Disponible en: https://doi.org/10.1017/ glj.2020.58.

McNamara, K. R. (1998). The Currency of Ideas: Monetary Politics in the European Union. Ithaca: Cornell University Press. Disponible en: https://doi. org/10.7591/9781501711930.

Mooij, A. A. M. (2019). The Weiss judgment: The Court's further clarification of the ECB's legal framework Case C-493/17 Weiss and others, EU:C:2018:1000. Maastricht Journal of European and Comparative Law, 26 (3), 449-465. Disponible en: https://doi.org/10.1177/1023263X19837208.

Nguyen, H. T. y Chamon, M. (2020). The ultra vires decision of the German Constitutional Court-Time to fight fire with fire? Jacques Delors Center (Hertie School) Policy Paper.

Nowag, J. (2020). Proportionality Review in the PSPP Judgment and its Link to Ultra Vires and Constitutional Core: Solange Babel's Tower Has Not Been Finalised. SSRN Paper. Disponible en: https://doi.org/10.2139/ssrn.3634218.

Ocampo, J. A., Stallings, B., Bustillo, I., Velloso, H. y Frenkel, R. (2014). La crisis latinoamericana de la deuda desde la perspectiva histórica. Santiago: Cepal. Disponible en: https://doi.org/10.18356/d2e46298-es.

Olesti Rayo, A. (2021). La Unión Europea y la financiación de las medidas para afrontar la crisis de la covid-19, Revista General de Derecho Europeo, 53.

Payandeh, M. (2011). Constitutional Review of EU law after Honeywell: contextualizing the relationship between the German Constitutional Court and the EU Court of Justice. Common Market Law Review, 48 (1), 9-38.

Pernice, I. (2011). Motor or Brake for European Policies? Germany's New Role in the EU after the Lisbon-Judgment of Its Federal Constitutional Court. Humboldt-Universität zu Berlin WHI-Paper, 3, 11. Disponible en: https://doi. org/10.5771/9783845233109-353.

Pernice, I. (2014). A Difficult Partnership between Courts: The First Preliminary Reference by the German Federal Constitutional Court to the CJEU. Maastricht Journal of European and Comparative Law, 21 (1), 3-13. Disponible en: https://doi.org/10.1177/1023263X1402100101.

Petersen, N. (2020). Karlsruhe's Lochner Moment? A Rational Choice Perspective on the German Federal Constitutional Court's Relationship to the CJEU After the PSPP Decision. German Law Journal, 21 (5), 995-1005. Disponible en: https://doi.org/10.1017/glj.2020.54.

Piccirilli, G. (2018). The 'Taricco Saga': the Italian Constitutional Court continues its European Journey. European Constitutional Law Review, 14 (4), 814-833. Disponible en: https://doi.org/10.1017/S1574019618000433.

Pliakos, A. y Anagnostaras, G. (2017). Saving Face? The German Federal Constitutional Court Decides Gauweiler. German Law Journal, 18 (1), 213-231. Disponible en: https://doi.org/10.1017/S207183220002191X.

Rauchegger, C. (2018). National constitutional rights and the primacy of EU law: M.A.S. Common Market Law Review, 6, 1521-1547. 
Riles, A. (2018). Financial citizenship: Experts, publics, and the politics of central banking. Ithaca: Cornell University Press.

Sáinz de Vicuña y Barroso, A. (2016). La política monetaria del BCE ante el Tribunal Constitucional Federal Alemán: la Sentencia de 21 de junio de 2016 en el caso «OMT». Revista de Derecho Comunitario Europeo, 55, 1067-1099. Disponible en: https://doi.org/10.18042/cepc/rdce.55.08.

Sánchez-Barrueco, M. L. (2021). ¿Integración a cambio de gestión de crisis? Novedades introducidas en el Marco Financiero Plurianual 2021-2027 en el contexto de la covid-19. Revista de Derecho Comunitario Europeo, 68.

Sarmiento, D. (2018). Adults in the (Deliberation) Room. A comment on M.A.S. Quaderni Costituzionali, 1, 225-231.

Scheller, H. P. (2006). The European Central Bank: History, Role and Functions. Fráncfort: Banco Central Europeo.

Schmid, C. U. (2001). All Bark and No Bite: Notes on the Federal Constitutional Court's 'Banana Decision'. European Law Journal, 7 (1), 95-113. Disponible en: https://doi.org/10.1111/1468-0386.00120.

Schneider, K. (2013). Yes, But...One More Thing: Karlsruhe's Ruling on the European Stability Mechanism. German Law Journal, 14 (1), 53-74. Disponible en: https://doi.org/10.1017/S2071832200001711.

Stein, T. (1994). La sentencia del Tribunal Constitucional Alemán sobre el Tratado de Maastricht. Revista de Instituciones Europeas, 21 (3), 745-770.

Taborowski, M. (2012). Infringement proceedings and non-compliant national courts. Common Market Law Review, 49 (6), 1881-1898.

Thym, D. (2009). In the name of the Sovereign Statehood: a Critical Introduction to the Lisbon Judgement of the German Constitutional Court. Common Market Law Review, 46, 1795-1822.

Tuominen, T. (2020). Reconceptualizing the Primacy-Supremacy Debate in EU Law. Legal Issues of Economic Integration 3, 245-266.

Tuori, K. (2014). The Eurozone Crisis: a Constitutional Analysis. Cambridge: Cambridge University Press. Disponible en: https://doi.org/10.1017/ CBO9781107297289.

Tuori, K. (2019). The ECB's quantitative easing programme as a constitutional game changer. Maastricht Journal of European and Comparative Law, 26 (1), 94-107. Disponible en: https://doi.org/10.1177/1023263X18822796.

Turmo, A. (2019). A Dialogue of Unequals - The European Court of Justice Reasserts National Courts' Obligations under Article 267 (3) TFEU. European Constitutional Law Review, 15 (2), 340-358. Disponible en: https://doi.org/10.1017/ S1574019619000117.

Varga, Z. (2020). The Effectiveness of the Köbler Liability in National Courts. Oxford: Hard. Disponible en: https://doi.org/10.5040/9781509939220.

Walker, N. (2002). The idea of constitutional pluralism. The modern law review, 65 (3), 317-359. Disponible en: https://doi.org/10.1111/1468-2230.00383. 
Weiler, J. H. H. (2009). Editorial. The 'Lisbon Urteil' and the Fast Food Culture. European Journal of International Law, 20 (3), 505-519. Disponible en: https:// doi.org/10.1093/ejil/chp072.

Wendel, M. (2020). The Two-Faced Guardian - Or How on half of the German Federal Constittucional Court became a European Fundamental Rights Court. Common Market Law Review, 6, 1383-1426. 